\title{
Asociaciones palinológicas en las formaciones Los Monos (Devónico) e Itacua (Carbonífero Inferior) en Balapuca (Cuenca Tarija), sur de Bolivia. Parte 1. Formación Los Monos
}

Mercedes di Pasquo

\author{
Consejo Nacional de Investigaciones Científicas y Técnicas. \\ Departamento de Geología, Facultad de Ciencias Exactas y Naturales, \\ Universidad de Buenos Aires, \\ Ciudad Universitaria, Pabellón 2, $1^{\circ}$ Piso, (1428) Capital Federal, Argentina. \\ medipa@gl.fcen.uba.ar.
}

RESUMEN

Se caracterizan cuali-cuantitativamente dos asociaciones palinológicas recuperadas de ocho muestras fértiles de la Formación Los Monos (Eifeliano tardío-Frasniano temprano), expuesta en la localidad de Balapuca, ubicada en la margen boliviana del río Bermejo en la sierra de San Telmo. Esta unidad depositada en la Cuenca Tarija, sobreyace a la Formación Pescado (o Huamampampa, Emsiano-Eifeliano), y subyace, cuando está preservada, a la Formación Iquirí (Frasniano-Famenniano). La sección litológica estudiada se compone principalmente de pelitas grises, laminadas o macizas, y areniscas con estructuras de corriente o bioturbadas. Restos de invertebrados y plantas fósiles fueron recuperados de distintos niveles, algunos de los cuales resultaron además, palinológicamente fértiles. La microflora en su totalidad aquí presentada se compone de 76 especies de palinomorfos, entre las cuales son dominantes las esporas trilete mientras que aparecen subordinados acritarcas, prasinofitas, criptosporas y quitinozoarios. Se describen dos especies nuevas de esporas, Leiotriletes balapucensis y Endoculeospora altobellii, ambas comprendidas en la asociación más jóven. La distribución estratigráfica de especies clave permitió reconocer dos asociaciones, una atribuida al Eifeliano tardío y la otra al Givetiano temprano tardío a Givetiano tardío. Ambas asociaciones comparten numerosas especies con otras microfloras coetáneas principalmente de Argentina, Bolivia, Brasil y fuera de América del Sur, en América del Norte y el oeste de Europa.

Palabras claves: Palinoestratigrafía, Formación Los Monos, Devónico, Cuenca Tarija, Sur de Bolivia.

\section{ABSTRACT}

Palynological assemblages present in Los Monos (Devonian) and Itacua (Lower Carboniferous) formations at Balapuca (Tarija basin), southern Bolivia. Part One, Los Monos Formation. Two associations of palynomorphs recovered from eight samples from Los Monos Formation (late Eifelian-early Frasnian), cropping out at Balapuca, located at the Bolivian margin of the Bermejo River in the San Telmo range, are characterized. In the Tarija Basin, this unit overlies the Pescado (or Huamampampa) Formation (Emsian-Eifelian) and underlies the Iquiri Formation (Frasnian-Famennian), when it is preserved. The studied section is mainly composed of grey laminated or massive pelites and sandstones with current structures or bioturbation. Paleoinvertebrates and fossil plant debris were recovered from different levels, and some of them yielded palynomorphs. The whole microflora here presented is composed of 76 species, of which trilete spores are dominant and acritarchs, prasinophytes, cryptospores and chitinozoans are subordinately present. Two new species of spores, Leiotriletes balapucensis and Endoculeospora altobellii, both belonging to the 
youngest assemblage, are described. Two assemblages are recognized based on the stratigraphical distribution of diagnostic species, one attributed to the late Eifelian and the other to the late early Givetian to late Givetian. Both associations share several species with other coeval microfloras mainly from Argentina, Bolivia, Brazil, and beyond South America, from North America and western Europe.

Key words: Palynostratigraphy, Los Monos Formation, Devonian, Tarija Basin, Southern Bolivia.

\section{INTRODUCCIÓN}

Se presenta la palinoestratigrafía de una sección litológica que aflora en Balapuca $\left(22^{\circ} 31^{\prime} 00^{\prime}\right.$ 'S, $64^{\circ} 26^{\prime}$ $00 " \mathrm{~W})$, localidad ubicada del lado boliviano en el límite con Argentina (noroeste de Salta). En esta primera parte del trabajo se incluye una introducción geológica, la ubicación estratigráfica de las muestras estudiadas y la metodología de campo y laboratorio empleada, válidos para ambas partes del trabajo. Además, se trata la caracterización cuali-cuantitativa palinológica de las dos asociaciones correspondientes a la Formación Los Monos y la ilustración de la mayoría de las especies determinadas. Asimismo, se presenta una comparación con otras microfloras coetáneas o similares en edad y composición lo cual permite confirmar la edad de dichas asociaciones. En la segunda parte de este trabajo, a presentarse en otro artículo a futuro, se caracterizará la asociación palinológica correspondiente a la Formación Itacua del Carbonífero Inferior, se establecerá su comparación, se discutirá la importancia del hallazgo de palinomorfos retrabajados en la caracterización cronológica del hiato identificado entre dichas unidades estratigráficas, se analizarán posibles causas y se incluirán las conclusiones generales de ambas partes.

Las sedimentitas del Devónico-Carbonífero aquí estudiadas forman parte de la Cuenca Tarija, y se registran tanto en afloramientos como en subsuelo junto con otras rocas del Fanerozoico, en el norte de
Argentina, centro-sur de Bolivia y noroeste de Paraguay (Fig. texto 1A).

Rocas del Silúrico y Devónico afloran en Argentina, en las Sierras Subandinas y el Sistema de Santa Bárbara y se extienden en el subsuelo de gran parte del Chaco Salteño y la Llanura Chacoparanense. Formaron parte de una cuenca sedimentaria marina de gran distribución areal y espesor que cubre gran parte del territorio boliviano y el noroeste de Paraguay. Registros paleontológicos indican una continuidad o conexión con los depósitos de la misma edad en la Cuenca Madre de Dios (entre los $10^{\circ} \mathrm{S}$ y $20^{\circ} \mathrm{S}$ ) constituyendo un segmento de posición NNW-SSE de casi 1.000 km de extensión cuyo límite norte habría sido el Alto de Paititi (Anzulovich et al., 2005). A su vezesta cuenca, habría estado conectada con otras en el norte de Perú y oeste de Brasil como se muestra en la figura texto 1A (e.g., Ottone, 1996; Vistalli, 1999; Suárez Soruco, 2000; Grahn y Gutiérrez, 2001; Grahn, 2005).

Recientemente, Dalenz Farjat et al. (2002) interpretaron los depósitos del Subandino sur y el Chaco (Fig. texto 1A) como una cuenca de retroarco sin acortamiento. Albariño et al. (2002) y Álvarez et al. (2003) analizaron la misma región y establecieron un modelo de distribución de facies en un contexto secuencial entre el Ludlovianoy Frasniano, integrando estudios paleontológicos en su mayoría inéditos.

FIG. texto 1. A1. Cuencas neopaleozoicas de América del Sur (modificado de Azcuy y di Pasquo, 2000). El recuadro negro indica el área de estudio. A2. Provincias geológicas de Bolivia denominadas: 1- Madre de Dios; 2- Beni; 3- Chaco; 4- Cratón de Guaporé; 5- Subandinas (norte y sur); 6- Cordillera Oriental; 7- Altiplano; 8- Pantanal; 9- Cordillera Occidental (tomado de Suárez Soruco, 2000). B. Mapa geológico de la región estudiada (modificado de Salfity et al., 1998). C. Plano de ubicación geográfica de la región del límite entre la provincia de Salta, Argentina y el sur de Bolivia en las sierras Subandinas occidentales. D. Cuadro estratigráfico del Devónico a Pérmico basado en (1) Starck (1999), Vistalli (1999) y Suárez Soruco (2000), (3) Díaz Martínez (1999) y Suárez Soruco (2000). Las unidades bioestratigráficas indicadas en (2) corresponden a di Pasquo (2003). E. Sección litoestratigráfica simplificada del perfil de Balapuca registrada en el flanco occidental del anticlinal de Balapuca en la sierra de San Telmo (Bolivia). Se muestra la ubicación de los niveles palinológicos estudiados, otros elementos paleontológicos (invertebrados y plantas) y posición geográfica en $\mathrm{km}$ (el km 0 corresponde a la Aduana Aguas Blancas (Argentina)-Bermejo (Bolivia), y el km 41 al aforo ubicado a la altura de las diamictitas de la Formación Tarija, sobre la ruta boliviana que conduce a otras localidades en Bolivia como Alarache y Tarija).

Abreviaturas: P: pelita; Af: arenisca fina; Am: arenisca media; Ag: arenisca gruesa; Cg: conglomerado. 


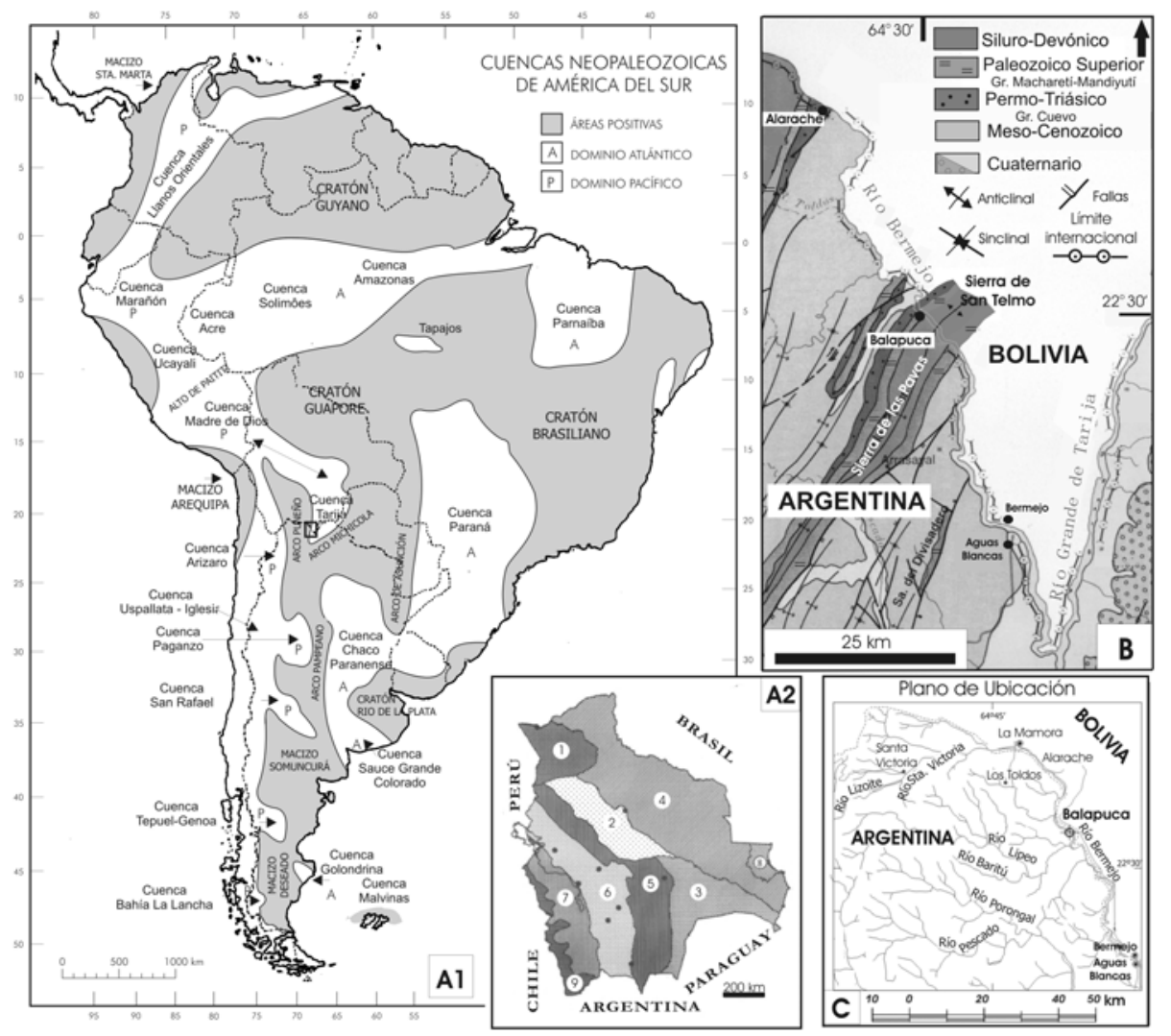

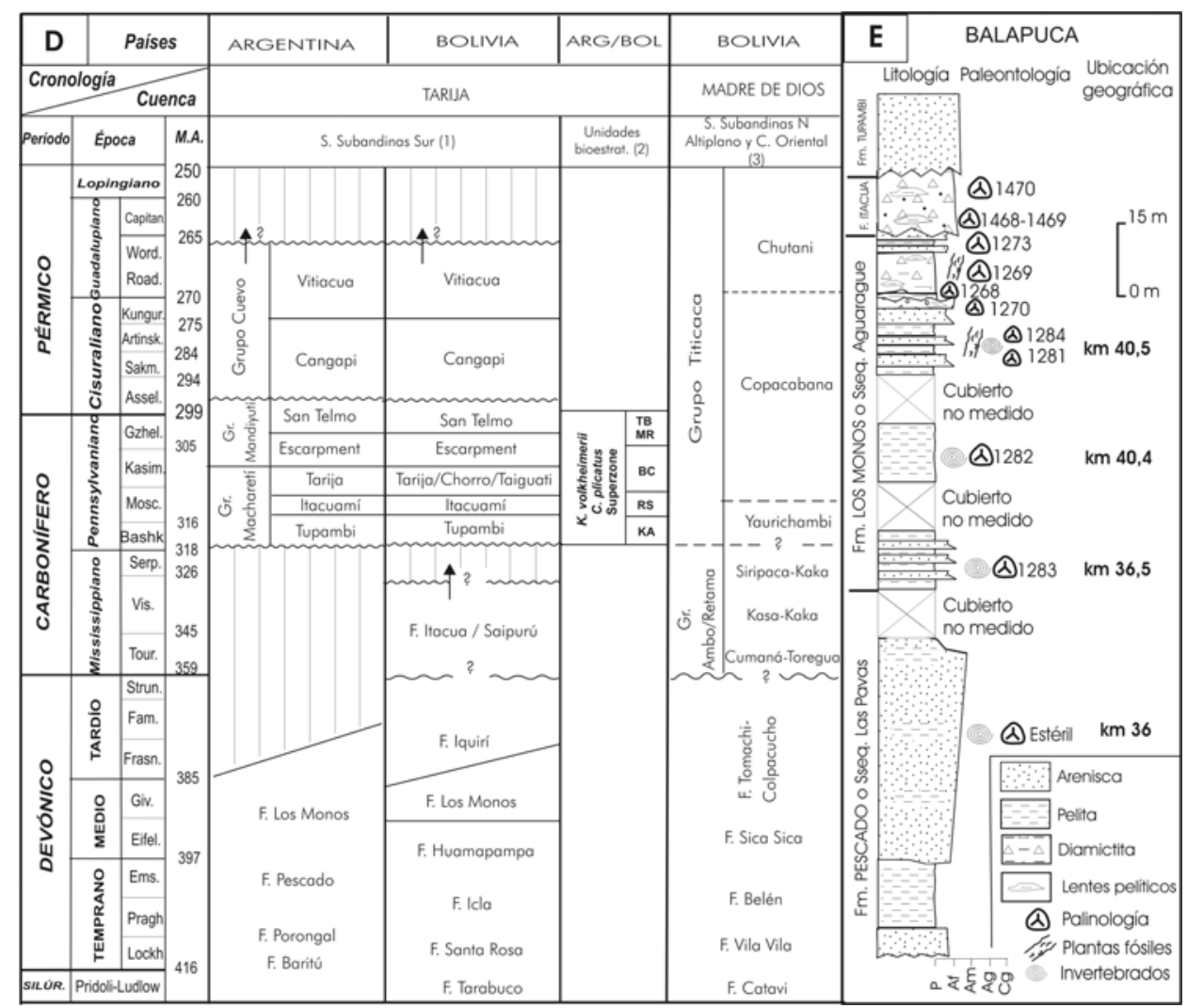


Sobre estas unidades del Devónico (o más antiguas) se asientan en discordancia las rocas del Carbonífero, principalmente del Carbonífero Superior en las Sierras Subandinas, en la parte oriental de la Cordillera Oriental y en el subsuelo de la Llanura Chaco-Salteña en el norte de la Argentina y Chaco en el sur de Bolivia (Fig. texto 1A-E). Las rocas del Carbonífero Superior en esta cuenca se reúnen en los Grupos Macharetí y Mandiyutí, en cambio, las formaciones Itacua y Saipurú representan para algunos autores el FamenianoCarbonífero Inferior (e.g., Suárez Soruco, 2000), en el sur de Bolivia. Estas unidades no han sido registradas en el norte de la Argentina, por ello no se incluyen en general en los esquemas estratigráficos de la región en la base del Grupo Macharetí (Carbonífero Superior temprano; Fig. texto 1D). di Pasquo (2003) presentó el estudio de lasección litológica suprayacente atribuida a los mencionados grupos formacionales y se sugiere su lectura para conocer sobre la composición litológica de las unidades, las asociaciones palinológicas identificadas, su edad y el esquema bioestratigráfico propuesto para esta región de la Cuenca Tarija.

Por otro lado, son aún escasas las publicaciones específicas con resultados palinológicos obtenidos de unidades del Devónico y Carbonífero en el noroeste de la Argentina, las cuales pueden consultarse en Ottone (1996) y di Pasquo (2003). Limachi et al. (1996) proponen esquemas bioestratigráficos del Silúrico y Devónico basados sólo en listas de especies de invertebrados, plantas y palinomorfos sin ilustraciones. Una contribución reciente es la de Grahn y Gutiérrez (2001), quienes presentan asociaciones silúrico-devónicas de quitinozoarios provenientes de las serranías de Santa Bárbara y Zapla (sur de Jujuy), muy similares a las halladas en regiones contemporáneas de Bolivia, Paraguay y Brasil. Grahn (2002) presenta nueva información palinoestratigráfica basada en el estudio de quitinozoarios del Silúrico Superior y Devónico del centro y sur de Bolivia, donde incluye una nueva especie obtenida de la Formación Los Monos en la misma localidad aquí estudiada. Finalmente, di Pasquo (2005) realizó una síntesis de las asociaciones palinológicas halladas en las Formaciones Los Monos e Itacua aquí estudiadas.

Sin embargo, el grado de avance respecto de la edad de las citadas unidades es aún insuficiente para comprender la evolución de las microfloras y su distribución paleobiogeográfica entre el Devónico y el Carbonífero, y en que medida es posible vincular esa evolución con los procesos tectónicos, las glaciaciones o cambios paleoclimáticos y las variaciones del nivel del mar que acontecieron en ese lapso, principalmente en Gondwana.

\section{MATERIALES Y MÉTODOS}

El trabajo de campo se concretó en dos campañas realizadas en 1998 y 2000 . En la primera se realizó el levantamiento del perfil de Balapuca desde la parte alta de la Formación Pescado (o Huamampampa, Emsiano a Givetiano temprano según diversos autores, e.g.; Grahn, 2002) hasta los depósitos del Grupo Cuevo (Pérmico; Fig. texto 1B-E) y se recolectaron muestras de mega y microfósiles. En la segunda campaña fue posible acceder y muestrear los niveles diamictíticos que se encuentran inmediatamente por debajo del Grupo Macharetí y que podían corresponder al Carbonífero Inferior. Toda la sucesión aquí representada parcialmente en la figura texto $1 \mathrm{E}$, se halla expuesta en el flanco occidental del Anticlinal de Balapuca en la Sierra de las Pavas del lado argentino, o sierra de San Telmo del lado boliviano (Fig. texto 1B). El perfil de Balapuca recibe este nombre por la presencia de un aforo en el km 41 de la ruta boliviana que comunica la ciudad de Bermejo con localidades como Nogalito y Alarache, camino a la ciudad de Tarija. El km 0 corresponde a la ubicación de la Aduana (Aguas Blancas-Bermejo, Fig. texto 1C) sobre este camino. El aforo se ubica en las diamictitas de la Formación Tarija y aguas abajo el perfil continúa con afloramientos cada vez más antiguos hastael Devónico posiblemente más bajo (hasta el km 33 aproximadamente), mientras que aguas arriba del aforo siguen los afloramientos de la Formación Tarija y unidades más jóvenes (Grupos Mandiyutí, Cuevo y unidades del Terciario; Fig. texto 1D).

El muestreo palinológico se realizó exhaustivamente a lo largo de la sección recolectando preferentemente aquellas litologías más favorables para la preservación de palinomorfos como las rocas pelíticas y diamictitícas de colores grises. En la figura texto2, se ilustran fotografías de campo que muestran casi en 
su totalidad la sección del perfil aquí estudiado indicando los niveles palinológicos con su número de colección y su ubicación geográfica en km (Fig. texto 1E). La información palinológica obtenida de las capas del Carbonífero Superior de este perfil fue publicada como parte de un trabajo bioestratigráfico de los
Grupos Macharetí y Mandiyutí de la parte sur de la Cuenca Tarija (di Pasquo, 2003; Fig. texto 1D), donde se formaliza un esquema bioestratigráfico para la cuenca y se establecen comparaciones con otras microfloras que permiten sustentar la edad de las biozonas.
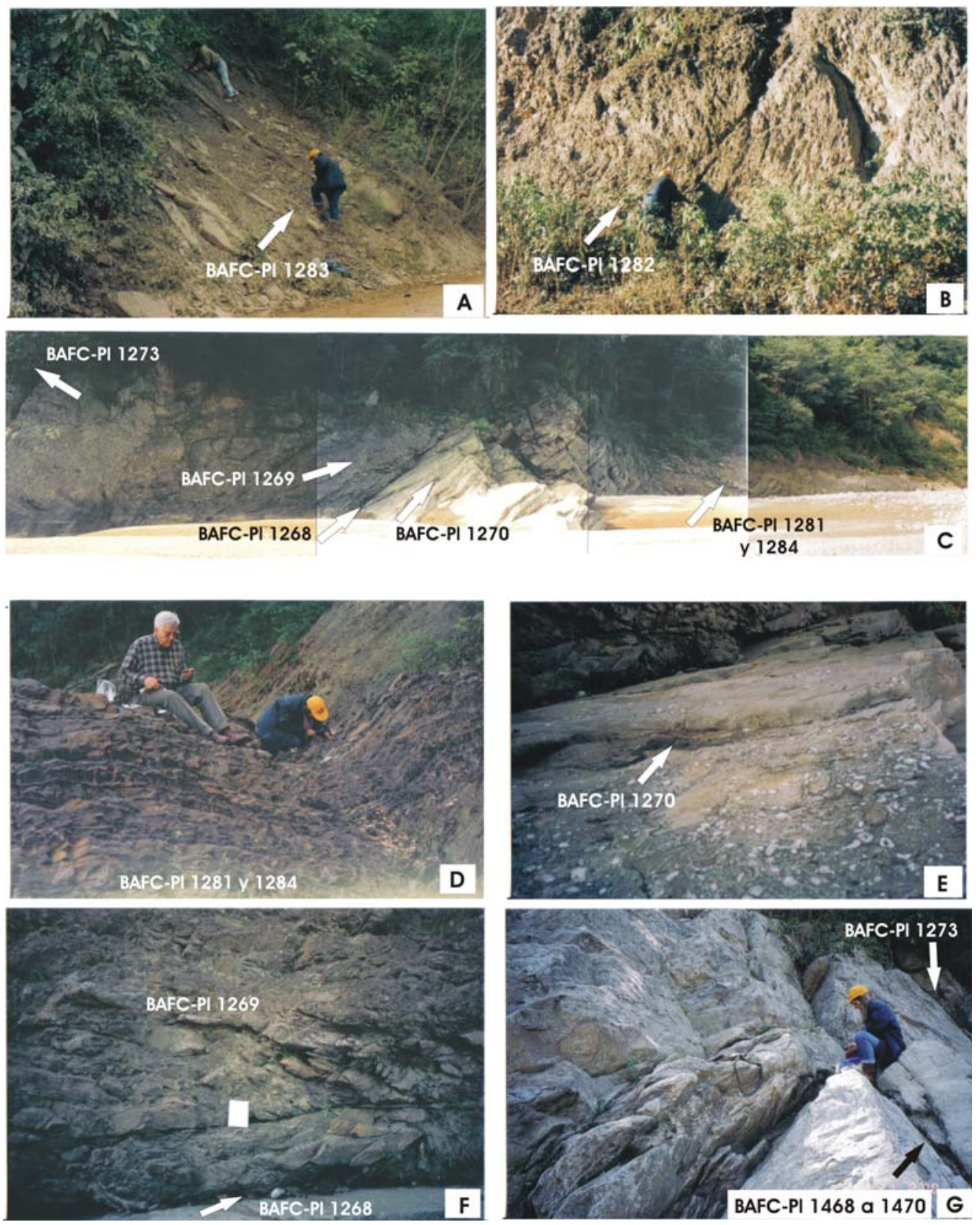

FIG. texto 2. Fotos de las distintas secciones del perfil aquí estudiado con la ubicación de los niveles muestreados palinológicamente. Para la descripción de cada foto véase el texto. 
Las muestras fueron procesadas según la metodología estándar, cuyo tratamiento final se realizó con $\mathrm{HCl}$ caliente para lograr un mejor desprendimiento de los palinomorfos del material húmico según fuera necesario. Los residuos fueron siempre filtrados con malla de $25 \mu \mathrm{m}$ y montados con gelatina-glicerina. Todas las muestras fueron rotuladas con la sigla BAFCPI precediendo al número de preparado correspondiente al repositorio (Palinoteca) ubicado en el Laboratorio de Palinoestratigrafía y Paleobotánica del Departamento de Geología, de la Facultad de Ciencias Exactas y Naturales de la Universidad de Buenos Aires. Los palinomorfos y el grado de madurez de la materia orgánica fueron reconocidos mediante el uso de un microscopio binocular Orthoplan Leitz No. 4303017 , con un aumento máximo de 1000x, y las coordenadas citadas en el texto corresponden a la reglilla universal 'England Finder'. Las láminas con microfotografías fueron obtenidas con cámaras digitales Pixera y Motic adosadas al microscopio y archivadas en formato de alta calidad (Tiff). Los ejemplares ilustrados con MEB obtenidos de sus residuos correspondientes, fueron montados en agua entre un cubre y un portaobjetos para tomar fotografías con el microscopio óptico de luz transmitida. Luego fueron pasados a un cubreobjetos el cual se adhirió a un taco con cinta bifaz para ser estudiado en un microscopio electrónico de barrido (MEB) Philips serie XL modelo 30 perteneciente al Museo Argentino de Ciencias Naturales 'Bernardino Rivadavia' (MACN). Para este estudio fueron metalizados con una delgada película de $200 \AA$ Oro-Paladio, realizado en un metalizador 'Termo VG Scientific SC 7620'. Posteriormente, los cubreobjetos fueron desprendidos y montados sobre un portaobjetos con gelatina-glicerina con el fin de reilustrar los mismos palinomorfos con el microscopio óptico. Se comprobó que la delgada película del metalizado permitió observar e ilustrar el material de manera casi semejante a la de un preparado palinológico sin metalizar.

En este trabajo se ha adoptado la escala de tiempo recomendada por la International Union of Geological Sciences (I.U.G.S.) en 2004 (e.g., House y Gradstein, 2004; Davydov et al. , 2004), aunque se utiliza el término informal 'Struniano' para denominaral Famenniano Tardío.

\section{MARCO GEOLÓGICO DE LA REGIÓN}

Los sucesivos eventos tectónicos y erosivos ocurridos especialmente en los Andes Centrales durante el Mesozoico y Cenozoico, fueron responsables de la fragmentación y complejidad que muestran hoy las cuencas paleozoicas (Díaz Martínez, 1999)y ayudaron a obliterar o enmascarar gran parte de las evidencias de la actividad tectónica acaecida durante el Paleozoico. Las Sierras Subandinas (Fig. texto 1A), donde se ubica la localidad aquí estudiada, corresponden a una estrecha franja constituida por alineaciones orográficas meridianas y subparalelas que, separadas por valles longitudinales, representan las estribaciones más orientales de la cadena Andina en el extremo norte de Argentina y en Bolivia. Las mismas representan también una verdadera 'faja plegada y fallada de lámina delgada' de la parte más externa del Orógeno Andino para las latitudes comprendidas entre los $18^{\circ}$ y los $23^{\circ} 30^{\prime} S$ (considerando el 'Subandino Sur' Boliviano y las Sierras Subandinas de Argentina), ubicándose entre la Cordillera Oriental, desarrollada al oeste y la Llanura Chaqueña situada hacia el este (Fig. texto 1A; Starck et al., 2002). Otros trabajos como Starck et al. (1993 a, b), Sempere (1995), Tankard et al. (1995), Starck (1995, 1999), Jaillard et al. (2000), Ramos (2000), Suárez Soruco (2000), Aceñolaza et al. (2000), di Pasquo y Azcuy, 1999), Azcuy y di Pasquo (2000), Starck etal. (2002), sintetizan diferentes aspectos de la evolución tectomagmática, sedimentaria y/o estratigráfica del Paleozoico de esta región.

De acuerdo con Jaillard et al. (2000), diferentes tasas de subducción en relación con la actividad de las placas a lo largo del margen occidental de Gondwana y el sentido de migración de los arcos magmáticos desarrollados en diferentes momentos durante el Paleozoico, han generado diferentes tipos de cuencas como por ejemplo, cuencas de trasarco extensionales durante la fase temprana (Cámbrico/Ordovícico) y tardía (Carbonífero Tardío a Pérmico), entre los $5^{\circ} \mathrm{y}$ $27^{\circ} \mathrm{S}$. Un régimen de compresión en cuencas de retroarco se interpreta en cambio para la fase intermedia entre el Ordovícico y el Carbonífero Temprano. En esta región los procesos tectomagmáticos que afectaron las rocas del Paleozoico Superior se conocen 
como Orogenia Eohercínica (Suárez Soruco, 1989), y si bien todavía no hay suficientes datos isotópicos de intrusiones acaecidas en el límite DevónicoCarbonífero, hay evidencias que indican deformación transpresional y levantamiento de capas del Devónico y Carbonífero Inferior principalmente en la Cordillera Oriental y el Altiplano y en menor medida en la región Subandina y Chaco (Fig. texto 1A). Esto confirma también el desarrollo de un margen activo para esta región en el Carbonífero (e.g., Suárez Soruco, 2000; Jaillard et al., 2000), apoyado también por la presencia de palinomorfos devónicos retrabajados en asociaciones del Carbonífero Tardío (e.g., di Pasquo y Azcuy, 1997; di Pasquo, 2003) y del Carbonífero Temprano como se muestra en este trabajo.

Dalenz Farjat et al. (2002) interpretaron los depósitos silúricos y devónicos del Subandino Sur y el Chaco del norte de la Argentina y sur de Bolivia (Fig. texto $1 \mathrm{~A}$ ) como una cuenca de retroarco sin acortamiento. En ese contexto, Albariño et al. (2002) y Álvarez et al. (2003) establecieron para esta misma región un modelo de distribución de facies en un contexto secuencial, interpretando el ambiente de la región como una plataforma silicoclástica marina dominada por oleaje entre el Ludloviano y el Frasniano, donde la depositación habría estado controlada por variaciones eustáticas marcadas por al menos tres eventos de regresiones forzadas indicadas por cuerpos arenosos depositados hacia el centro de cuenca, integrando estudios paleontológicos, en su mayoría inéditos, para correlacionar las secuencias. Una mayor inestabilidad tectónica habría afectado la sedimentación en los límites Ordovícico/Silúrico y Devónico/ Carbonífero, y especialmente con respecto a este último lapso, los esfuerzos traspresivos habrían originado levantamientos locales (e.g., Arco Puneño, Salfity, 1980; Fig. texto 1A), dando lugar a la erosión de los rellenos de cuenca de manera variable y generando hiatos que resultan sermás amplios cuanto más próximo al margen de cuenca se encuentra la sección estratigráfica (Starck etal., 1993 a; Sempere, 1995).

Jailllard etal. (2000) consideraron que la Orogenia Eohercínica no fue un evento tectomagmático único que generó un cinturón montañoso, sino un conjunto de diferentes procesos y eventos que tuvieron lugar durante el Paleozoico Medio a Superior a través de los Andes Centrales y dieron lugar a distintas manifestaciones tectomagmáticas y sedimentarias. Cabe señalar que Sempere (2004) cuestiona el uso de fases tectónicas como eventos de corta duración que se sucedieron en el tiempo, y en su lugar propone tratar de entender y explicar las discordancias o discontinuidades entre los estratos o su deformación tectónica (fallas, pliegues, etc.), las cuales son evidencias concretas que resultan de la observación de campo y que pueden ser resultado de una tectónica activa o bien de procesos sedimentarios relacionados con cambios climáticos.

En la región del oeste de Argentina, Ramos (2004) presentó una revisión de la historia geológica del terreno Cuyania el cual involucra rocas del Paleozoico Inferior temprano hasta su colisión en el margen occidental del oeste de Argentina en el LlandelianoCaradociano. La deformación de los depósitos precarboníferos según este autor, habría continuado a través del resto del Paleozoico Inferior hasta la amalgamación de un nuevo terreno Chilenia hacia el final del Devónico. Ramos et al. (1984) postularon como parte de las consecuencias de dicha amalgamación, el levantamiento de la Proto-Precordilleray Proto-Cordillera Oriental al este del Arco Puneño (Fig. texto $1 \mathrm{~A}$ ) y la subsidencia que dio origen a las cuencas carboníferas a lo largo de esta franja cordillerana del continente Sudamericano (proceso tectónico denominado fase Chánica, véase también Salfity et al., 1987; Azcuy y Caminos, 1988; Starck et al., 1993 b).

Por otro lado, los cambios climáticos (glaciación y deglaciación)y los cambios del nivel del mar (eustasia) afectaron las sucesiones sedimentarias (e.g., Isbell et al., 2003). Como ejemplo de ello se cita la erosión relacionada con la regresión global ocurrida en el límite Carbonífero Temprano/Tardío, la cual habría generado una discordancia (en partes de bajo ángulo) entre las unidades del Carbonífero Superior y las rocas subyacentes del Devónico, Silúrico o inclusive Ordovícico (e.g., Starck, 1999). Isaacson etal. (1999) y Streel et al. (2000) discutieron la importancia de la glaciación para explicar la sedimentación discontinua entre el Frasniano y el Tournaisiano en Gondwana y su correlación con los cambios del nivel del mar que afectaron también los ciclos de sedimentación en regiones extra-gondwánicas (e.g., oeste de Europa, Rusia), tomando como base el análisis de cambios litológicos ofaciales, extinciones o cambios faunísticos y florísticos y variaciones en las proporciones del $\mathrm{CO}_{2}$ atmosférico y $\mathrm{dC}^{12}$, entre otras evidencias (véase una discusión más adelante).

Un esquema similar llevado a todo el Gondwana fue recientemente presentado por Isbell et al. (2003), 
quienes mencionan que la evaluación de la distribución geográfica y cronoestratigráfica de los depósitos gondwánicos revelarían que la glaciación no habría sido continua desde el Frasniano al Pérmico sino que se habrían desarrollado tres sucesiones, una entre el Frasniano al Tournaisiano posiblemente (Glacial I), la segunda entre el Namuriano y el Westphaliano temprano (Glacial II), y la última entre el Estefaniano y el Artinskiano (Glacial III). La ablación completa de las calotas o glaciares de gran tamaño durante el Glacial III habría producido cambios eustáticos importantes de alrededor de $100 \mathrm{~m}$, magnitud similar a la profundidad de los paleovalles excavados sobre rocas del Paleozoico Inferior y que sugieren un espacio de acomodación comparable. A su vez, el derretimiento de glaciares de menor tamaño habría generado fluctuaciones de menor magnitud.

Es interesante destacar también para la sucesión carbonífera de la Cuenca Tarija (desde la Formación Itacua hasta San Telmo; Fig. texto 1D), la propuesta de Schulz et al. (1999) de un modelo de ciclos glaciales-interglaciales basado en el estudio de numerosas secciones de campo. Según estos autores, en el contexto de una cuenca intracratónica, se desarrolló una subsidencia termal sin tectonismo involucrado, controlada por ascensos y descensos del nivel del mar combinados con una fuerte influenciaglacial durante este período. Propusieron un esquema de evolución paleoambiental definiendo un Megaciclo Carbonífero dentro del cual delimitaron seis superciclos denominados de base a techo, Itacua, TupambiTarija, Chorro-Taiguati, 'Las Peñas' (= Escarpment)y San Telmo I y ll a partir de la jerarquización de superficies marcadas por una génesis fuertemente erosiva que constituyen los límites de cada superciclo. Estos a su vez, están constituidos por dos hemisuperciclos, uno desarrollado bajo condiciones glaciales y otro, interglaciales. Una de las causas de las variaciones en el nivel del mar o de base en este esquema habría sido el rebote isostático generado por la ablación de los hielos.

\section{ESTRATIGRAFÍA}

La columna sedimentaria en esta región está representada por sedimentitas clásticas desde el Paleozoico Inferior hasta el Terciario (véase en parte en la Fig. texto 1D). Los antecedentes estratigráficos de las unidades del Devónico al Carbonífero Superior pueden ser ampliados en Starck et al. (1993a, b), Sempere (1995), Starck (1995, 1999), Vistalli (1999), Suárez Soruco (2000), Azcuy y di Pasquo (2000), Miranda et al. (2000), entre otros.

Starck (1995) presentó un esquema tectonoestratigráfico del Fanerozoico para el norte de la Argentina y sur de Bolivia, en el cual el lapso SilúricoJurásico se divide en dos intervalos separados por una discordancia de carácter regional. Dentro del primer intervalo, Silúrico-Devónico, caracterizó tres supersecuencias granocrecientes denominadas en orden estratigráfico ascendente, Supersecuencia Cinco Picachos, Las Pavas y Aguaragüe. En este esquema, la Formación Pescado fue incluida en la segunda supersecuencia y la Formación Los Monos en laúltima supersecuencia y ambas nominaciones son utilizadas aquí como se ilustra en la figura texto 1E. Vistalli (1999) resume aspectos de la sedimentología de las unidades silúricas y devónicas y la estratigrafía secuencial antes citada estableciendo una correlación entre las supersecuencias y las unidades estratigráficas tradicionales reconocidas en el norte de la Argentina y en el sur de Bolivia. Por su parte, Grahn (2002) sintetizó la evolución de la nomenclatura estratigráfica y de las edades de las unidades del Ciclo Siluro - Devónico (o Cordillerano según Suárez Soruco, 2000) en Bolivia según distintos autores.

La sucesión estratigráfica carbonífera ha sido reinterpretada por Starck (1995) como dos supersecuencias separadas por discontinuidades de escaso valor cronológico, coincidiendo con los Grupos Macharetí (Formaciones Tupambi, Itacuamí y Tarija)y Mandiyutí (Formaciones Escarpment y San Telmo) en la Argentina. En Bolivia, el primero de estos grupos segúnalgunos autores, incluye las Formaciones Itacua y/o Saipurú, no registradas en la Argentina (Fig. texto 1D) como se tratará a continuación.

\section{GRUPO O SUPERSECUENCIA MACHARETÍ}

(Reyes, 1972)

Sus afloramientos se extienden principalmente en el ámbito de las Sierras Subandinas, y en menor medida se distribuyen en la parte oriental de la Cordillera Oriental y en el subsuelo de la Llanura 
Chaqueña en la Argentina. Estos mismos depósitos continúan en territorio boliviano hasta aproximadamente la latitud del área de Santa Cruz de la Sierra (Padula y Reyes, 1958; Ayavirí, 1972). Fue definido por Harrington (in Padula y Reyes, 1958) en la quebrada de Macharetí, Bolivia. Suárez Soruco y Díaz Martínez (1996) presentaron los antecedentes y otra información litológica de esta unidad, la que se caracteriza por un alto contenido pelítico (diamictitas, lutitas y limolitas) respecto de estratos subordinados de areniscas y waques y por su coloración predominantemente grisácea. Esta entidad alcanza espesores de alrededor de $1.000 \mathrm{~m}$ en afloramientos (Aramayo Flores, 1989). En la Argentina, el Grupo Macharetí yace en discordancia sobre rocas del Devónico (Formación Los Monos y equivalentes) u otras más antiguas (Starck et al., 1993b). El contacto con el Grupo suprayacente Mandiyutí es paraconcordante. La Formación Tarija subyace en contacto erosivo a la Formación Escarpment; sin embargo según di Pasquo (2003) no se registra un hiato importante a través de los estudios palinológicos realizados en distintas localidades.

Con respecto a la extensión estratigráfica de los Grupos Macharetí y Mandiyutí, debe señalarse que, Harrington (1922, en Padula y Reyes, 1958), definió ambos grupos, Macharetí y 'Mandiutí', como conjuntos independientes en distintas localidades tipo, y separó a su vez unidades dentro de cada conjunto. En esa definición original la Formación Taiguati, o'Taiguati Shales', formaba parte del Grupo Macharetí, mientras que sólo las Formaciones Escarpment y San Telmo componían el otro grupo. Sin embargo, Padula y Reyes (1958), consideraron que la Formación Taiguati correspondería a la parte basal del Grupo Mandiyutí, en acuerdo con la definición del grupo publicada por Mather (1922). Poco después, Ahlfeld y Branisa (1960), en su contribución a la geología de Bolivia, siguieron el esquema estratigráfico propuesto por Padula y Reyes (1958), aceptando la extensión estratigráfica del Grupo Mandiyutí, pero excluyeron del Grupo Macharetí a la unidad basal definida por Harrington como 'T3Shale', nominada Itacua porWhite (1929, in Padula y Reyes, 1958; véase más abajo).

Más tarde, Reyes (1972) presentó un nuevo estudio regional sobre el Carbonífero y Pérmico de Bolivia y noroeste de la Argentina (o 'Cuenca Oriental'), y propuso un reordenamiento de las unidades estratigráficas. Si bien no fuera expresado por el autor citado, de la lectura del trabajo se desprende que retoma el concepto de Harrington (in Padula y Reyes,
1958) para definir los Grupos Macharetí y Mandiyutí. El primero queda conformado, en Bolivia, por las siguientes unidades, de techo a base: Taiguati, Tarija/ Chorro, Itacuamí, Tupambi e Itacua, y el segundo, exclusivamente por las Formaciones Escarpment y San Telmo.

Cabe señalar que Ayavirí (1972), realizó una contribución similar que fue publicada en el mismo volumen que el trabajo de Reyes (1972), y en ella presentó un cuadro estratigráfico que coincide con el de este último autor.

En la Argentina sólo han sido reconocidas dos ó tres de las unidades citadas, pues depende de las observaciones realizadas por distintos autores en diferentes localidades (Starck et al., 1993 a). Ellas son, de techo a base: formaciones Tarija, Itacuamí y Tupambi. La Formación Tupambi se compone de areniscas y subordinadas pelitas y conglomerados y presenta fuertes cambios faciales y de espesor (10 a 500 metros), tanto en subsuelo como en afloramientos. Los espesores máximos de esta unidad están directamente vinculados a las depresiones interpretadas como paleovalles, de las que son buenos ejemplos la sección del río Baritú y la quebrada Pluma Verde, con 350 y $320 \mathrm{~m}$ de areniscas del miembro inferior, respectivamente (Starck etal., 1993b). Por lo tanto, la edad de este grupo en la parte argentina de la Cuenca Tarija, es diferente de aquélla del grupo completo, principalmente en Bolivia (véase la Formación Itacua más abajo). Sobre la base de estudios palinológicos, esta entidad ha sido considerada en la Argentina de edad carbonífera tardía, debido a la presencia conspicua de granos de polen monosacado hallados en los niveles superiores de la Formación Tupambi (di Pasquo y Azcuy, 1999; di Pasquo, 2002, 2003). Recientemente, di Pasquo (2005) citó la presencia de semillas platispérmicas en la parte alta de la Formación Tarija confirmando esta antigüedad.

\section{FORMACIÓN ITACUA}

(White, 1929, in Padula y Reyes, 1958)

En Bolivia fue denominada informalmente por Harrington (1922, in Padula y Reyes, 1958) como 'T3 Shale', una unidad basal en el Grupo Macharetí, no reconocida hasta ahora en afloramientos en la Argentina. Poco después fue definida por White (1929, in Padula y Reyes, 1958) como Formación Itacua, en la quebrada homónima, compuesta por diamictitas arenosas violáceas, rosadas y grises. Reyes (1972) y Suárez Soruco y Díaz Martínez (1996), entre otros, 
aceptaron su inclusión en la base del Grupo Macharetí, en tanto otros autores la han considerado separada de este grupo o bien no han opinado sobre esto. Suárez Soruco y López Pugliessi (1983) la redefinieron como Formación Saipurú en la quebrada Taputá, pues consideraron que en su definición original se habían incluido sedimentitas meteorizadas de la parte superior de la devónica Formación Los Monos.

Sempere (1990, in Sempere, 1995) revalidó el nombre Itacua apoyado en el resultado de estudios de campo en la Sierra de Aguaragüe (Bolivia), donde corroboróla existencia de capas estratificadas de color gris y gris rojizo, que no pueden interpretarse como la parte alterada del techo de la Formación Los Monos. Este mismo autor basado en el análisis de las sucesiones carboníferas de la Cuenca Tarija, concluyóque, en gran parte de la Faja Subandina, la depositación de las unidades comprendidas entre la base de la Formación Itacua y el tope de San Telmo (o sus equivalentes), habría sido continua, y por lo tanto no puede existir ningún hiato importante dentro de esta sucesión.

Suárez Soruco y Díaz Martínez (1996) y Suárez Soruco (2000) apoyaron la definición de ambas unidades, Formaciones Itacua y Saipurú, las cuales representan arealmente las regiones del Subandino sur y centro en Bolivia, respectivamente. Los espesores son muy variables, entre ausente y hasta 200 metros en afloramiento mientras que en subsuelo puede alcanzar hasta 500 metros. En la Argentina es dudosa su presencia en secciones de pozo en áreas del Subandino y la llanura Chaco-Salteña (e.g., Azcuy y Laffitte, 1981; Fig. texto 1A), pero no fue comprobada su presencia en afloramientos (Schulzetal., 1999). Su límite inferior en Bolivia es erosivo y disconcordante sobre unidades devónicas, y en su techo se apoya en discordancia la Formación Tupambi. Tanto la Formación Itacua como Saipurú se habrían depositado sobre un relieve suave pero irregular con altos y bajos topográficos o en depresiones sintectónicas en un ambiente marino de plataforma somera según Suárez Soruco (2000, p. 86), durante el Carbonífero Temprano para algunos autores (di Pasquo y Azcuy, 1997; Schulz et al., 1999; Azcuy y di Pasquo, 2000), en tanto que para otros incluye el Famenniano (Suárez Soruco y Díaz Martínez, 1996; Limachi et al., 1996; Álvarez et al., 2003). Schulz et al. (1999) interpretaron al superciclo Itacua integrado por dos hemiciclos, uno interglacial constituido por depósitos de ríos efímeros mientras que el hemiciclo glacial se compone de depósitos subglaciales retrabajados por corrientes tractivas relacionadas a etapas de deshielo. Seña- laron que se restringe a posiciones de interior de cuenca en territorio boliviano y que sólo encontraron registros de esta unidad en dos perfiles (Pilcomayo y Los Monos). Se sugiere reestudiar las secciones de Camirí y Río Azero donde Lobo Boneta $(1975,1989)$ identificó asociaciones palinológicas del Famenniano tardío al Carbonífero Temprano para confirmar la edad de esta unidad tan poco representada en la cuenca.

\section{BREVE DESCRIPCIÓN DEL PERFIL ESTUDIADO}

La secuencia del Devónico hasta la base del Carbonifero Tardío aquí estudiada (Figs. texto 1B, E), presenta las siguientes características litológicas: A partir del km 35 de la ruta a Tarija (en Bolivia), se observa un conjunto de estratos gris amarillentos en general compuesto por pelitas en la base seguido de waques fosilíferos y areniscas con un arreglo estratocreciente (buzando hacia el oeste), el cual se repite cinco veces considerándose a todo el paquete sedimentario parte de la Formación Pescado (o Huamampampa, Fig. texto 1D). Sólo una muestra fue obtenida del último ciclo, en el km 36, de una capa de waques micáceas amarillentas bioturbadas con trilobites y braquiópodos que resultó palinológicamente estéril. En el km 36,5 se registraron los primeros bancos pelíticos de color gris oscuro de la Formación Los Monos. Se trata de una sucesión de ritmitas de capas tabulares y lenticulares, decimétricas a centimétricas, compuestas por pelitas negras micáceas laminadas y areniscas grisáceas de grano fino a medio con ondulitas, en las cuales se encuentran briznas, artejos de crinoideos y bioturbación (Figs. texto 1E y 2A, BAFC-PI 1283). Le siguen capas de limolitas de color castaño con hyolites y trilobites (BAFC-PI 1282) en el núcleo del anticlinal (se observan las capas plegadas en la figura texto 2B). Luego se registran capas centimétricas rítmicas o sucesión heterolítica de pelitas micáceas oscuras y areniscas micáceas ondulíticas con artejos de crinoideos fragmentados y moldes, bioturbación y restos de plantas mal preservadas (posiblemente atribuibles a la licofita Haplostigma furquei, BAFC-PI 1281 y a $6 \mathrm{~m}$ por arriba, 1284; Fig. texto $2 \mathrm{Cy}$ D). Delgados lentes de conglomerado fino se intercalan también en esta sección.

Por arriba le sigue otro paquete de estratos de areniscas conglomerádicas de color amarillo claro con estructura 'hummocky', conteniendo lentes de pelita gris (BAFC-PI 1270) y otras conglomerádicas (Fig. texto $2 \mathrm{C}$ y E). En contacto onduloso irregular se encuentra un paquete de diamictita color negro con 
intraclastos pelíticos y clastos de variado tamaño y composición ligados por una matriz areno-pelítica negra (Fig. texto $2 \mathrm{C}$ y F). Se observan también algunas lentes de pelita o areniscas algo deformadas (de espesor decimétrico y longitud métrica aproximadamente) y en su matriz, en la parte media, se hallan restos de las licofitas citadas más arriba. Se tomaron muestras del contacto (BAFC-PI 1268) y de la matriz en la parte superior de la diamictita (BAFC-PI 1269). Le sigue un paquete de areniscas micáceas grises y pelitas negras (BAFC-PI 1273) de poco espesor y en contacto irregular aparentemente discordante, el siguiente conjunto de estratos se compone de diamictitas de color gris blanquecino con una matriz arenosa de grano fino y clastos de diversos tamaños, forma y composición. Este conjunto presenta una fuerte consolidación y está atravesado por numerosas venillas de cuarzo. Se intercalan o incluyen lentes pelíticos de donde provienen las muestras BAFC-PI 1468,1469 y 1470 , distanciadas entre sí por apenas uno a tres metros (Fig. texto $2 \mathrm{G}$ ).

La secuencia del Carbonífero Superior correspondiente al Grupo Macharetí comienza con un paquete de alrededor de $30 \mathrm{~m}$ de areniscas posiblemente atribuibles a la Formación Tupambi, pues no ha brindado palinomorfos que permitan corroborar paleontológicamente su edad, y le sigue un banco de pelitas gris verdosas de las que se recuperó la primera asociación palinológica atribuida al Carbonífero Tardío temprano referida por di Pasquo $(1999,2003)$ a la Biozona R. radiosa-A. spinulistratus (Fig. texto 1D).

\section{RESULTADO PALINOLÓGICO}

Se determinaron 76 especies autóctonas de esporas, acritarcas, prasinofitas y quitinozoarios en la Formación Los Monos. La figura texto 3 presenta la distribución estratigráfica y cuantitativa de las especies de palinomorfos determinadas (con la autoría completa) y se incluye el registro de algunas de estas especies consideradas como retrabajadas presentes en la suprayacente Formación Itacua (Figs. texto 1D, E, 2), ordenadas de acuerdo con los grupos mayores identificados. Se muestra también el número correspondiente a la ilustración de cada especie y la presencia de otros grupos paleontológicos. Con un asterisco se destacan aquéllas que se citan y/oilustran por primera vez en Bolivia. El análisis cuantitativo se basó en el conteo de aproximadamente 250 ejemplares por muestra. En la columna'Referencias' figura la literatura seleccionada (trabajos sistemáticos o donde al menos se incluyen ilustraciones de las especies citadas junto con los trabajos bioestratigráficos aquí discutidos) utilizada en la figura texto 4 donde se muestran las distribuciones estratigráficas de las especies más representativas de las tres asociaciones aquí determinadas. En ambas figuras las especies se presentan en orden de aparición en la sucesión estratigráfica. La información así presentada permite establecer las características composicionales de las asociaciones definidas y sustentar la edad de cada una basado en la comparación con otras microfloras similares y/o coetáneas. La información palinológica provista en la segunda parte del trabajo, permitirá también discutir posibles causas de los hiatos identificados entre las unidades estratigráficas estudiadas especialmente sobre la base del valor de especies retrabajadas. En la figura texto $5 \mathrm{~A}$ se muestran en forma de tabla los porcentajes de grupos palinológicos mayores y detritos vegetales (cutículas, leño, restos sin estructura desde castaños hasta negros y materia orgánica amorfa) mientras que en las figuras texto $5 \mathrm{~B}$ y $\mathrm{C}$ se representan en forma de diagramas de torta los porcentajes promedio (prom) para cada asociación de la Formación Los Monos. En la figura texto 6 se presenta una correlación de las biozonas del Devónico de Europa Occidental y América del Norte (A), Rusia (B), Australia (C), Brasil (D) y Bolivia (E) con la ubicación temporal de las asociaciones reconocidas en la Formación Los Monos en Balapuca.

A continuación se presenta una síntesis de los rasgos tafonómicos y preservacionales por nivel en cada asociación. El índice de alteración térmica (TAI) utilizado corresponde a la escala de Utting et al. (1989, in Utting y Wielens, 1992). El tratamiento sistemático de las especies nuevas en la región estudiada se encuentra en un Apéndice al final del trabajo. Cabe señalar que la autora ha contribuido recientemente en trabajos sistemáticos donde fueron tratadas gran parte de las especies aquí determinadas y donde se citan trabajos sistemáticos previos de relevancia también para este trabajo (e.g., Azcuy y di Pasquo, 2005, 2006; Amenábar et al., 2006, en prensa). 


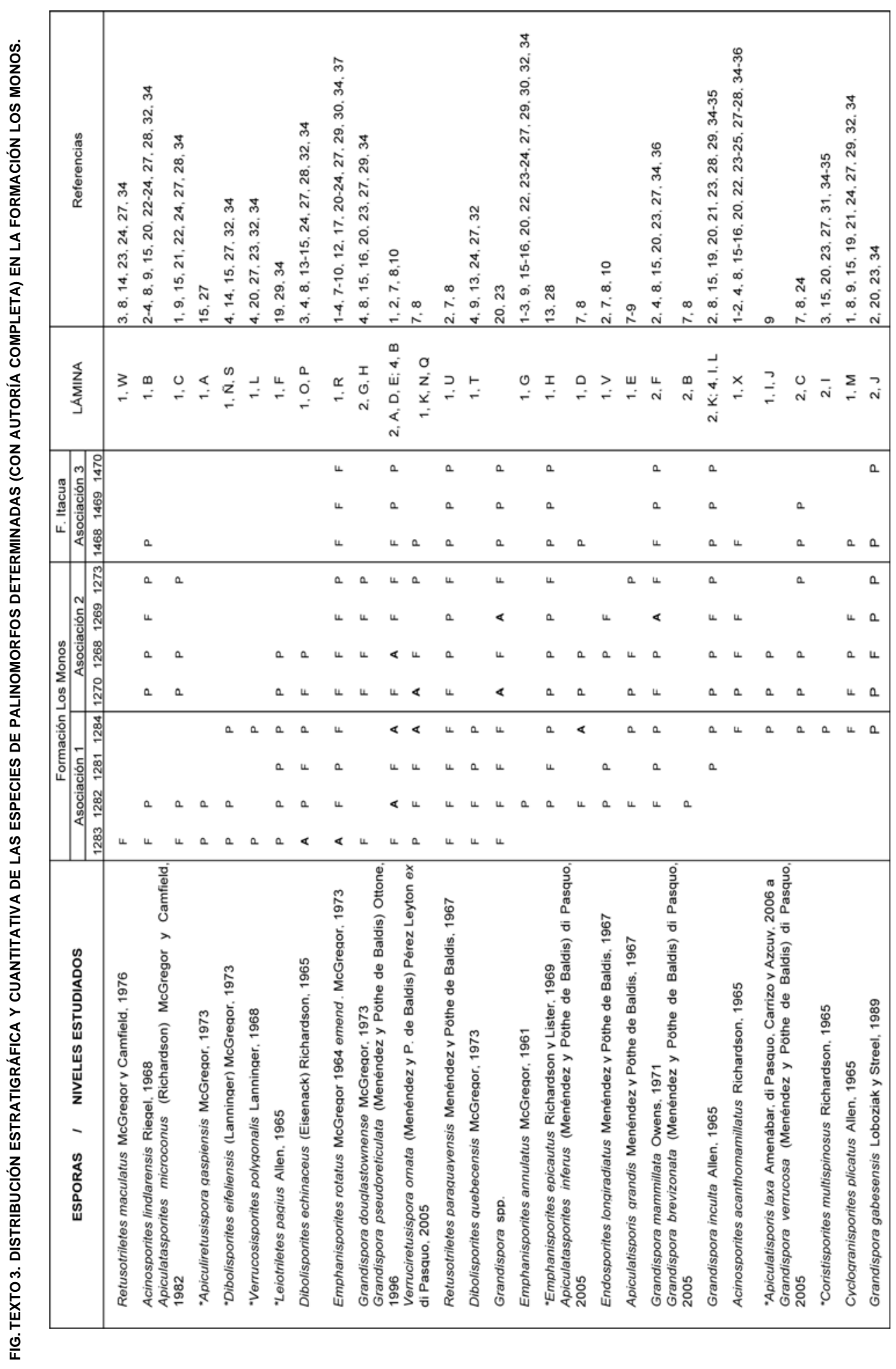




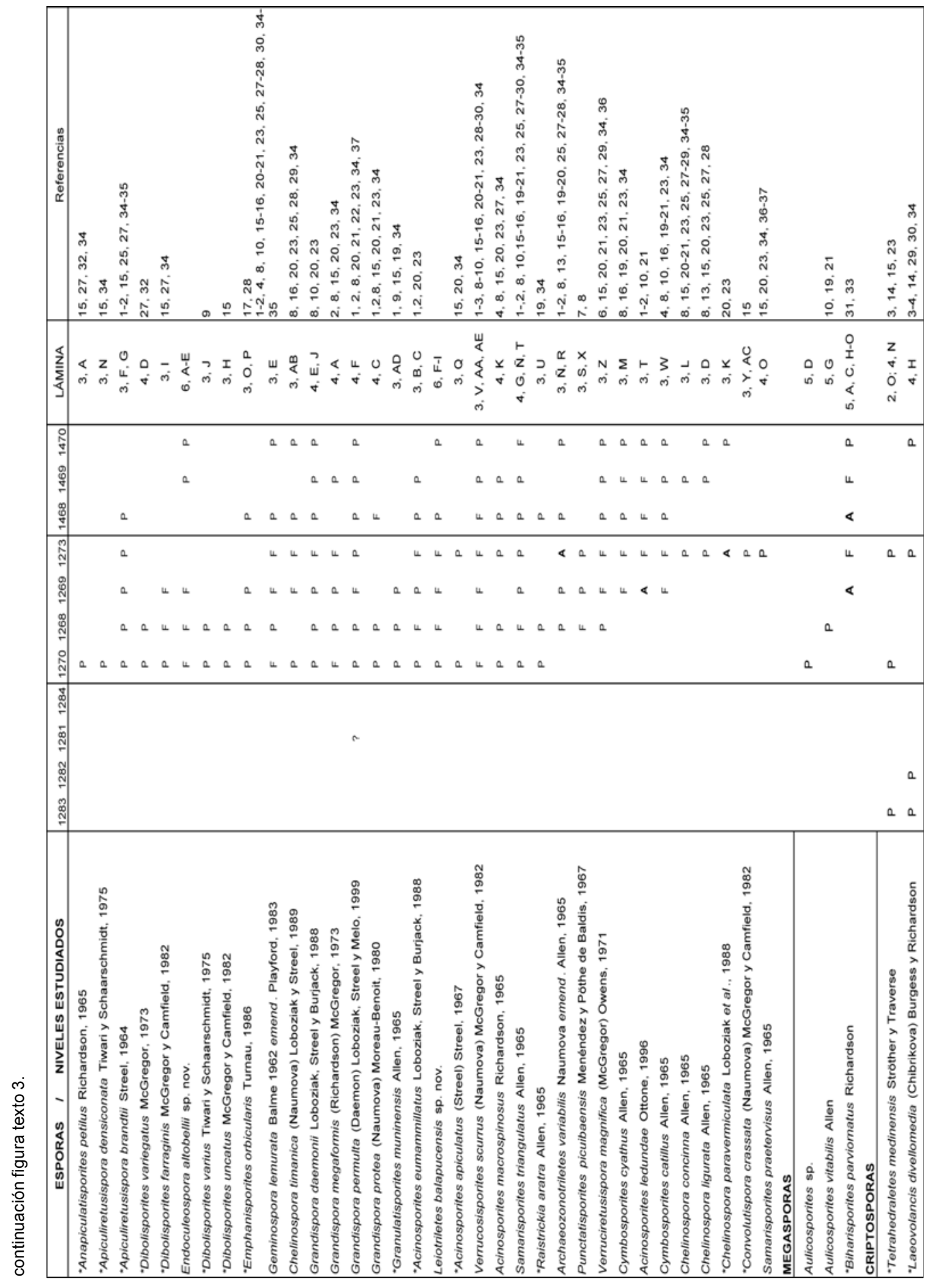



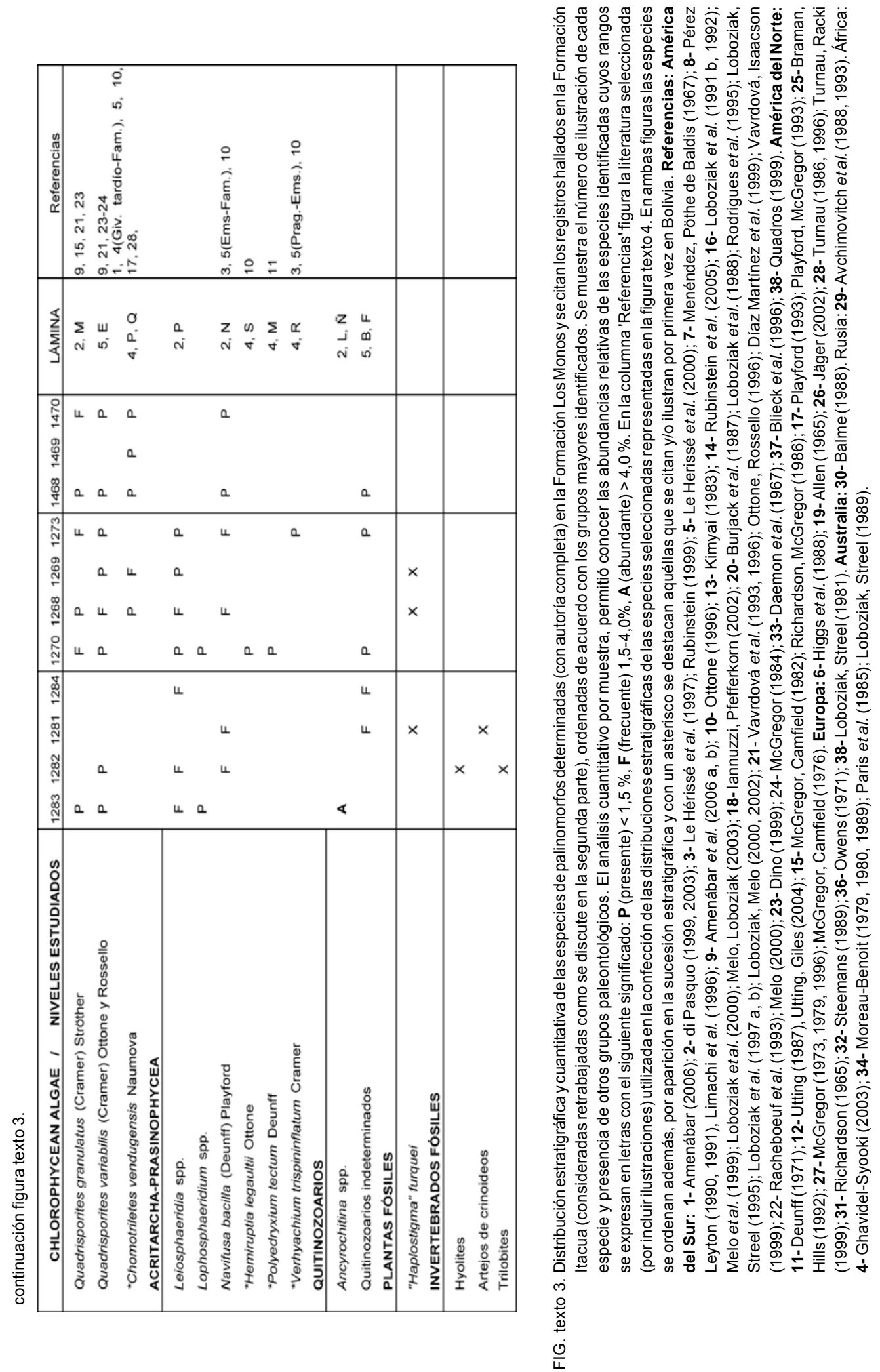


\section{CARACTERÍSTICAS DE LAS ASOCIACIONES PALINOLÓGICAS}

De acuerdo con di Pasquo (2005), la distribución estratigráfica de las especies halladas permitió reconocer tres asociaciones palinológicas, las dos más antiguas aquí tratadas. En general, se encontró que la mayoría de las muestras del Devónico presentan palinomorfos con una preservación desde mala a regular con un grado de madurez térmica entre 3-y 3 (color castaño claro a oscuro en la escala TAI), donde la mayoría se observan corroidos y muchos se encuentran fragmentados. Estas características impidieron obtener buenas ilustraciones de muchas de las especies determinadas. Las asociaciones presentan, en su mayoría, una gran cantidad de detritos vegetales (cutículas, leño, restos sin estructura desde castaños hasta negros) y materia orgánica amorfa (Fig. texto 5). La representatividad de los grupos mayores de palinomorfos es variable (Fig. texto 3 ) y contribuye en la interpretación paleoambiental de la sucesión estratigráfica del Devónico. Teniendo en cuenta la baja cantidad y diversidad de formas planctónicas (acritarcas, prasinofitas, quitinozoarios y escolecodontes), en ambas asociaciones, se interpreta un ambiente de plataforma marina somera para la asociación 1 y ambientes algo más marginales (albúfera o lagunas costeras) para la asociación 2 basado en una mayor proporción de formas de origen continental (esporas, prasinofitas, abundantes detritos vegetales). Esta interpretación también se apoya en la presencia de fósiles de invertebrados marinos como ocurre en la asociación 1 , los cuales están ausentes en la asociación 2 (Fig. texto 3).

\section{ASOCIACIÓN 1}

La asociación más antigua fue recuperada de las muestras BAFC-PI 1283, 1282, 1281 y 1284 y está compuesta principalmente por elementos de origen continental (28 especies de esporas trilete y dos de criptosporas) y subordinadas especies de origen marino (3 especies de prasinofitas / acritarcas, 2 de algas clorofíceas, y al menos tres especies no determinadas de quitinozoarios, mostrando en su conjunto una preservación relativamente buena. Se destaca la abundancia de ejemplares de gran tamaño (mayores a 70 micrones) y la presencia exclusiva en esta asociación de Retusotriletes maculatus, Apiculiretusispora gaspiensis, Dibolisporites eifeliensis,
Dibolisporites quebecensis, Verucosisporites polygonalis, Emphanisporites annulatus, Grandispora brevizonata y Coristisporites multispinosus. En particular cada uno de los niveles presenta las siguientes características tafonómicas y composicionales (Figs. texto 1E, 3, 5; Láms. 1, 2):

BAFC-PI 1283: Muestra de mano con briznas. En la preparación se observa un dominio de materia orgánica amorfa y restos de cutículas (70\%) y palinomorfos con grado variable de madurez térmica (-2 hasta -3) entre las que predominan las esporas trilete acavadas, en especial Dibolisporites echinaceous y Emphanisporites rotatus. Son escasos los quitinozoarios del género Ancyrochitina y los acritarcas y/o prasinofitas (Leiosphaeridia sp., Lophosphaeridium sp.).

BAFC-PI 1282: Muestra con hyolites y trilobites. Preparado con materia orgánica amorfa y restos de cutículas (70\%) y esporas en general mal preservadas con una alteración térmica entre 3-y3. Se registran abundantes ejemplares de Grandispora pseudoreticulata y otras especies del mismo género. Aparecen escasas formas de acritarcas no espinosos (Leiosphaeridia, Navifusa). No se registran quitinozoarios.

BAFC-PI 1281 y 1284: Muestras con licofitas herbáceas (Haplostigma furquei Frenguelli) y artejos de crinoideos. Preparado con materia orgánica amorfa, restos leñosos, cutículas y palinodetritos negros (75\%). El resto corresponde principalmente a esporas en general mal preservadas con una alteración térmica entre 3-y 3 , entre las que se registran abundantes ejemplares de diversas especies especialmente Grandispora pseudoreticulata, Verruciretusispora ornata y Apiculatasporites inferus. Aparecen escasas formas de acritarcas (Leiosphaeridia, Navifusa) y quitinozoarios indeterminados.

\section{ASOCIACIÓN 2}

La segunda asociación se presenta más diversa y comprende 31 especies de esporas trilete no identificadas en la asociación 1, 3 especies de megasporas, 2 de criptosporas, 3 de algas clorofíceas, 6 de prasinofitas/acritarcas y al menos una especie indeterminada de quitinozoario. La asociación se completa con abundantes restos de cutículas y leños (52\% en promedio) de diversos tamaños con una baja propor- 
ción de materia orgánica amorfa ( $5 \%$ en promedio). Cada nivel presenta las siguientes características tafonómicas y composicionales (Figs. texto 3, 5; Láms. 3 a 6):

BAFC-PI 1270: Presenta abundantes detritos vegetales (leños, cutículas, etc.), y numerosos ejemplares del género Grandispora, especialmente Grandispora pseudoreticulata y Grandispora mammillata, y Verruciretusispora ornata en vistas polares y laterales. No se registran acritarcas espinosos o con procesos, sólo algunas leiosphaeridias y escasos quitinozoarios. Se destaca una mayor diversidad de esporas, en general enteras y mejor preservadas que en los niveles anteriores y la aparición de Geminospora lemurata, Grandispora daemonii, Acinosporites eumammillatus y Samarisporites triangulatus, especies importantes estratigráficamente (Fig. texto 4 ).
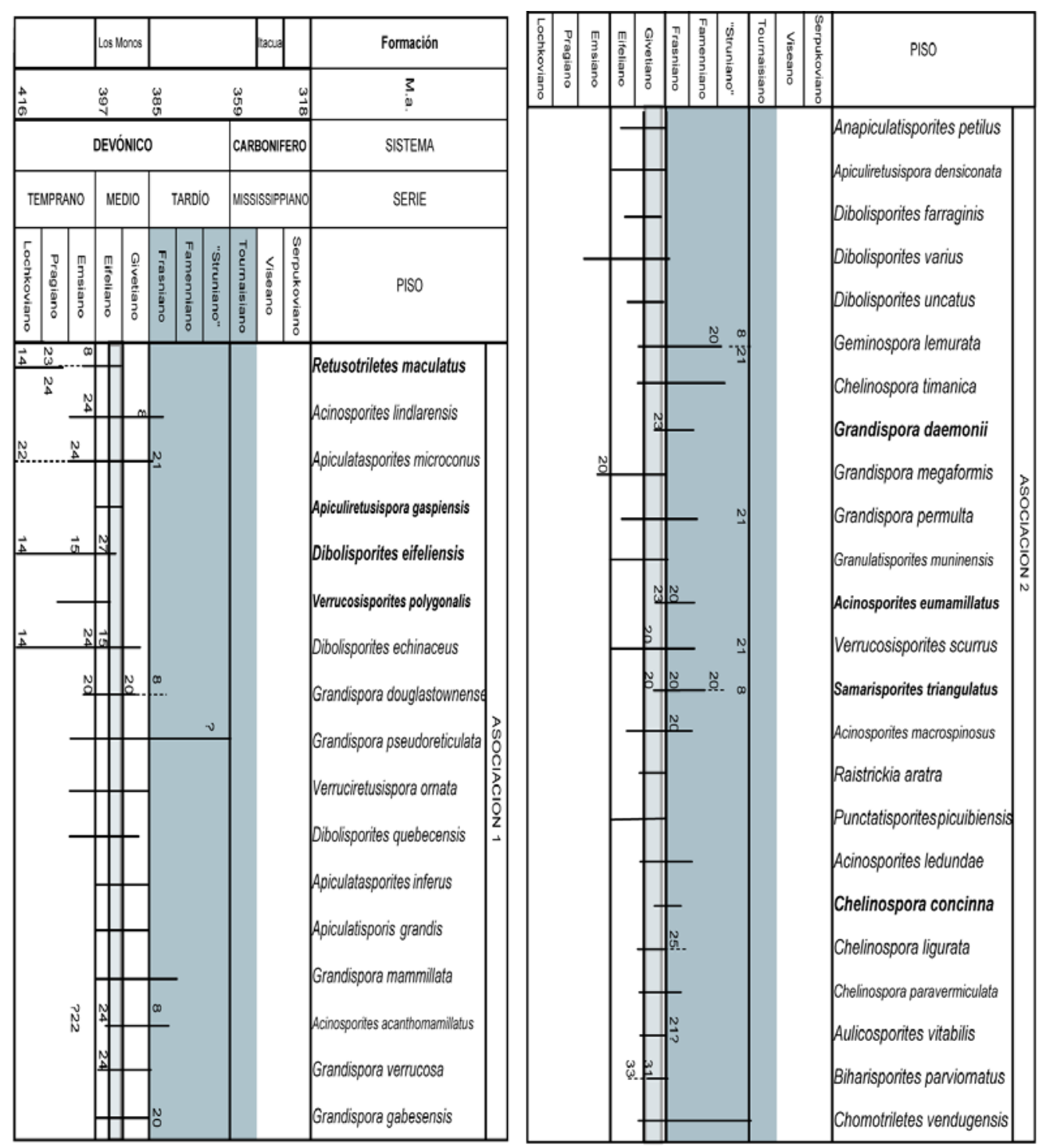

FIG. texto 4. Rangos estratigráficos de especies seleccionadas aquí determinadas en las Formación Los Monos en Balapuca (Bolivia) basado principalmente en trabajos de América del Sur y otros relevantes del resto del mundo citados (números) en la columna 'Referencias' de la figura texto 3. Las especies se ordenan por aparición en la sucesión estratigráfica. Las líneas punteadas indican registros dudosos. Se resaltan en negrita especies con significado estratigráfico para cada asociación. El recuadro en gris oscuro indica la extensión del hiato y los recuadros en gris claro corresponden a la extensión temporal de las asociaciones. 
BAFC-PI 1268 y 1269: La roca presenta restos de licofitas (Haplostigma furquei) y el preparado contiene abundante material detrítico (leños, cutículas, 'charcoal', materia orgánica amorfa) por sobre los palinomorfos, entre los que son dominantes las esporas. Se destaca la primera aparición de Chomotriletes vedugensis y de abundantes ejemplares de Acinosporites ledundae así como la abundancia de Grandispora pseudoreticulata y Grandispora mammillata, y la especie de megaspora Biharisporites parviornatus, todos de preservación regular a buena y color castaño claro a oscuro. Escasos acritarcas y ausentes quitinozoarios.

BAFC-PI 1273: Se registra un incremento de palinomorfos en su mayoría esporas trilete y megasporas, respecto del material detrítico (43\%). Sólo dos especies son abundantes, Archaeozonotriletes variabilis y Chelinospora paravermiculata, de las cuales la última hace su aparición en este nivel junto con otras cuatro especies. De ellas se destaca también Chelinospora concinna con valor estratigráfico (Fig. texto 4). Escasos acritarcas y quitinozoarios.

\begin{tabular}{|c|c|c|c|c|c|c|c|c|c|c|}
\hline \multirow{3}{*}{ A - \% grupos palinológicos } & \multicolumn{10}{|c|}{ Formación Los Monos } \\
\hline & \multicolumn{5}{|c|}{ Asociación 1} & \multicolumn{5}{|c|}{ Asociación 2} \\
\hline & 1283 & 1282 & 1281 & 1284 & Prom. & 1270 & 1268 & 1269 & 1273 & Prom. \\
\hline Esporas autóctonas & 29 & 29 & 24 & 25 & 27 & 49,5 & 34 & 30 & 56 & 42 \\
\hline Esporas retrabajadas & 0 & 0 & 0 & 0 & 0 & 0 & 0 & 0 & 0 & 0 \\
\hline Acritarcas/Prasinofitas/Quitinozoarios & 1 & 1 & 1 & 0 & 1 & 0,5 & 1 & 1 & 1 & 1 \\
\hline Fitoclastos (leño, cutículas, opacos) & 30 & 35 & 50 & 35 & 37 & 50 & 60 & 60 & 40 & 52 \\
\hline Materia orgánica amorfa (MOA) & 40 & 35 & 25 & 40 & 35 & 0 & 5 & 9 & 3 & 5 \\
\hline
\end{tabular}
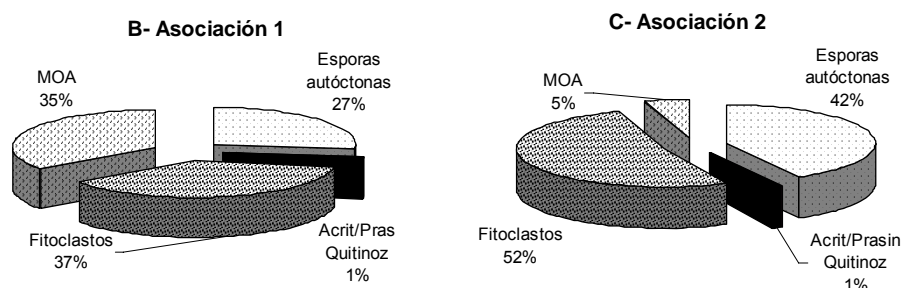

FIG. texto 5. A. Tabla de porcentajes de grupos palinológicos mayores y detritos vegetales (cutículas, leño, restos sin estructura desde castaños hasta negros y materia orgánica amorfa) de los niveles estudiados; B, C. Diagramas donde se representan los porcentajes promedio de cada grupo por asociación.

\section{EDAD, COMPARACIÓN Y CORRELACIÓN DE LAS ASOCIACIONES}

A la dificultad que significa no poder delimitar adecuadamente las formaciones Los Monos e lquirí e Itacua y Saipurú en algunas secciones de campo en el sur de Bolivia, se suma la de no contar con ilustraciones de los palinomorfos citados en esquemas bioestratigráficos propuestos para esta región (e.g., Suárez Soruco y Lobo Boneta, 1983; Lobo Boneta, 1989; Limachi et al., 1996). Esto impide comparar las asociaciones palinológicas obtenidas en distintas localidades con mayor precisión, especialmente del sur de Bolivia y norte de la Argentina. Pérez Leyton $(1990,1991)$ presentó un análisis palinológico del perfil del Bermejo cercano a la localidad de Santa Cruz de la Sierra, donde ilustró diversas formas especialmente continentales del Devónico Temprano hasta el
'Struniano'. Limachi et al. (1996) presentaron un esquema de biozonación que integra varios grupos paleontológicos obtenidos de un gran número de perfiles de diversas localidades del centro y sur de Bolivia. En el caso de la palinología, y teniendo en cuenta el esquema bioestratigráfico de Suárez Soruco y Lobo Boneta (1983), propusieron 4 zonas para el Silúrico con base principalmente en acritarcas y quitinozoarios y 7 zonas para el Devónico basadas preferentemente además, en el contenido de esporas (Fig. texto 6). La última zona denominada Retispora lepydophyta, correspondería al Struniano basado en la presencia de esta especie junto con Spinozonotriletes uncatus, Reticulatisporites sp., Umbellasphaeridium saharicum, Archaeozonotriletes cf. amplectus, 
Convolutispora vermiformis, Vallatisporites cf. pusillites, Vallatisporites sp., Lophozonotriletes sp., Maranhites mosesii, Knoxisporites (citada como Archaeozonotriletes) literatus.

Otros trabajos sistemáticos donde se ilustran palinofloras del Devónico de Bolivia y norte de Argentina son todavía escasos o requieren ser actualizados y de ningún modo son suficientes para conocer como fue la evolución de las microfloras en esta región (Fig. texto 3).

La asociación 1 aquí recuperada de la Formación Los Monos, es atribuida al Eifeliano tardío basado en la ausencia de Geminospora lemurata y el registro previo de las especies diagnósticas listadas y resaltadas en negrita en la figura texto 4. No se descarta que la muestra BAFC-PI 1283 pueda corresponder al Eifeliano temprano por la ausencia de Acinosporites acanthomammillatus y la presencia de especies como Acinosporites lindlarensis, Apiculatasporites microconus, Dibolisporites echinaceus, Retusotriletes maculatus, Grandispora douglastownense, Apiculiretusispora gaspiensis, especies registradas en la Biozona Grandispora douglastownenseAncyrospora eurypterota(Emsiano Tardío-Eifeliano Temprano), y Calyptosporites velatus-Rhabdosporites langii (Eifeliano Temprano; Richardson y McGregor 1986; Fig. texto 6). Según el esquema bioestratigráfico de Limachi et al. (1996) correspondería a la zona Emphanisporites annulatus-Evittia sommerii, con una sola especie común: Apiculatasporites microconus (Fig. texto 6). También puede correlacionarse con el nivel palinológico atribuido al Eifeliano tardío por Blieck et al. (1996) en Cochabamba, Bolivia (véase la columna de referencias en la Fig. texto 3).

Los demás niveles de la asociación 1 comparten especies con la Biozona 'Hymenozonotriletes' pseudoreticulatus del Eifeliano según Limachi et al. (1996), registrada en secciones de las formaciones Los Monos-Iquirí en las localidades La Escalera y Mataral. La mayoría de dichas especies a su vez, fueron descritas e ilustradas por primera vez por Menéndez y Pöthe de Baldis (1967), en el subsuelo de Paraguay, y fueron citadas en asociaciones de Bolivia y recientemente en el Devónico (Givetiano) de la Formación Chigua (Amenábar et al. , 2006, en prensa).

Por otro lado, la asociación 1 sería en parte referible a las Biozonas GS (Grandispora-Samarisporites) y Per (Grandispora permulta) recientemente defini- das en Amazonas por Melo y Loboziak (2003, Fig. texto 6). En la primera aparecen Acinosporites apiculatus, Grandispora douglastownense, G. megaformis y $G$. protea y otras con registros algo más antiguos como Acinosporites lindlarensis, Diatomozonotriletes franklinii, Emphanisporites annulatus. De estas especies sólo G. douglastownense, Acinosporites lindlarensis y Emphanisporites annulatus aparecen en la asociación 1. Las restantes lo hacen en la asociación 2, excepto por un registro dudoso de Grandispora permulta en el BAFC-PI 1281 (Fig. texto 3).

Todas las citadas especies continúan registrándose en la Biozona Per, en tanto aparecen la especie homónima junto con Camarozonotriletes? concavus, Craspedispora ghadamisensis, Grandispora libyensis, Verrucosisporites premnus y una mayor diversidad del complejo Grandispora/Samarisporites spp. Es atribuida al Eifeliano tardío temprano hasta la base del Givetiano y sería correlativa de la parte superior de la Zona VL (velatus-langii) y la siguiente Zona DN (devonicus-naumovii) definidas en el viejo continente ORS (Richardson y McGregor, 1986), y de la Zona Oppel AD-porción Pre-Lem del oeste de Europa (Streel et al., 1987; Fig. texto 6).

A partir de la muestra BAFC-PI 1270 se registra Geminospora lemurata, especie que en su primera aparición es indicadora del límite Eifeliano-Givetiano (Loboziak et al., 1991a). Sin embargo, en esta asociación se encuentran también Samarisporites triangulatus, Acinosporites eumammillatus y Grandispora daemonii (Fig. texto 4). La primera especie aparece tanto en la Biozona optivustriangulatus (equivalente a la Biozona TA Streel et al., 1987) en el esquema de Richardson y McGregor (1986), como en la Biozona Trg (Givetiano temprano tardío a la base del Frasniano) en el esquema de Melo y Loboziak (2003). En este último, además aparecen en forma abundante Cymbosporites catillus y $C$. cyathus, como también Chelinospora paravermiculata, especies que en Balapuca se registran en los dos últimos niveles de la asociación 2 (Figs. texto 3, 4 y 6).

La aparición de Verrucosisporites scurrus permitiría referir la asociación 2 a la Biozona Verrucosisporites premnus-Verrucosisporites scurrus Limachi et al. (1996) (Fig. texto 6), registrada según estos autores en las formaciones Los Monos (parte alta) y base de la Formación Iquirí en las secciones de La Escalera y Chajrahauyco (Bolivia), atribuida al 
Givetiano por la presencia conspicua de Verrucosisporites scurrus y Samarisporites triangulatus. Pérez Leyton (1990) considera a Cymbosporites catillus en su esquema de biozonación como indicador del Eifeliano superior aunque se registra en asociaciones más jóvenes. La asociación 2 es comparable también con la descrita por Ottone (1996) en la Formación Los Monos en la Quebrada Galarza (Argentina) atribuida al Givetiano tardío-Frasniano temprano. Comparte alrededor de 20 especies de esporas, megasporas y prasinofitas; sin embargo, la asociación 2 carece de las típicas especies de esporas, acritarcas y quitinozoarios del Frasniano. Por otro lado, en el esquema de biozonación de Rusia presentado por Avchimovitch et al. (1993; Fig. texto 6), Verrucosisporites scurrus y Grandispora inculta aparecen en la Zona Rhabdosporites langii atribuida al Eifeliano tardío mientras que Verruciretusispora magnifica, Chelinospora concinna y Samarisporites triangulatus aparecen en forma sucesiva en la Zona Geminospora extensa del Givetiano.

La presencia de especies cuyas distribuciones estratigráficas no pasan al Frasniano junto con la ausencia de otras que aparecen en ese tiempo (e.g., Verrucosisporites bulliferus (Taugourdeaux-Lantz) Richarson y McGregor 1986, Contagisporites optivus (Tchibrikova) Owens 1971), permiten acotar la edad de la parte superior de la unidad al Givetiano tardío (Figs. texto 3, 4 y 6).

Por lo tanto, la asociación 2 es atribuida al lapso Givetiano temprano tardío-base del Frasniano y el límite Eifeliano-Givetiano podría encontrarse en algún punto de la sección entre el nivel BAFC-PI 1270 y el anterior BAFC-PI 1284 ya que este último carece principalmente de formas guía como Geminospora lemurata y Samarisporites triangulatus (Figs. texto $1 \mathrm{E}, 3$ y 6$)$.

\begin{tabular}{|c|c|c|c|c|c|c|c|c|}
\hline \multicolumn{3}{|c|}{ REGIÓN } & Europa-NAM & Rusia & Australia & Brasil & Bolivia & Bol-Arg \\
\hline 20 & SERIE & PISO & A & B & C & D & E & $\mathbf{F}$ \\
\hline \multirow{14}{*}{ 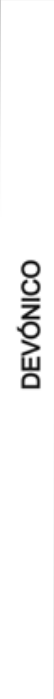 } & \multirow{5}{*}{$\frac{0}{\frac{\alpha}{\alpha}}$} & "STRUNIANO" & $\begin{array}{l}\text { lepydophyta-nilidus } \\
\text { pusillites-lepydophyta }\end{array}$ & $\begin{array}{l}\text { PLE PM } \\
\text { lepydophytate } \\
L L^{L M p l a n a t u s}\end{array}$ & R. lepydophyta & $\begin{array}{l}\text { R. lepydophyta- } \\
\text { V. vallatus } \\
\text { R. lepydophyte }\end{array}$ & $\begin{array}{c}? \\
\text { R. Lepydophyta }\end{array}$ & Hiato \\
\hline & & \multirow{2}{*}{ FAMENIANO } & flexuosa-comuta & \multirow{2}{*}{$\begin{array}{l}\text { C. vancomata } \\
\text { L. immensus } \\
C Z \\
W\end{array}$} & \multirow{3}{*}{ Microffora Brewer } & $\begin{array}{c}\text { V. hysthicosus } \\
\text { R. radiata }\end{array}$ & $?$ & \\
\hline & & & torquata-gracillis & & & $\begin{array}{l}\text { T. torquata- } \\
\text { A. pseudocrista }\end{array}$ & $?$ & \\
\hline & & \multirow{2}{*}{ FRASNIANO } & ovalis-bulliferus & \multirow{2}{*}{$\begin{array}{l}O G_{S D} \\
\stackrel{D E}{O K}\end{array}$} & & R. bricel-D. mucronatus & \multirow{3}{*}{$\begin{array}{l}\text { Maranhites- } \\
\text { Samarisporites }\end{array}$} & \\
\hline & & & C. optivus- & & Spinozontriletes sp. & $\begin{array}{l}\text { V. bulliforus- } \\
\text { G. plifformis }\end{array}$ & & \\
\hline & \multirow{4}{*}{$\frac{\mathrm{O}}{\mathrm{W}}$} & \multirow{2}{*}{ GIVETIANO } & & \multirow{2}{*}{ G. extensa } & G. lemurata & S. triangulatus & & A2 \\
\hline & & & lemurata-magnificus & & $\begin{array}{l}\text { Ancyrospora sp. } \\
\text { Aratrisporites so. }\end{array}$ & $\begin{array}{l}\text { G. lemurata- } \\
\text { Ch. ligurata }\end{array}$ & $\begin{array}{l}\text { V. premnus- } \\
\text { V. scumus }\end{array}$ & $\begin{array}{l}\text { Sin } \\
\text { información }\end{array}$ \\
\hline & & \multirow{2}{*}{ EIFELIANO } & $\begin{array}{l}\text { devonicus-naumovil } \\
\text { velatus-langii }\end{array}$ & R. langili & $\begin{array}{l}\text { Hystricosporites sp. } \\
\text { Brochozonotriletes }\end{array}$ & & \multirow[t]{2}{*}{ H. pseudoreticulatus } & \multirow[t]{2}{*}{ A1 } \\
\hline & & & $\begin{array}{l}\text { douglastownense- } \\
\text { eurypterota }\end{array}$ & P. tortus & & $\begin{array}{l}\text { Grandispora- } \\
\text { Samarisporites }\end{array}$ & & \\
\hline & \multirow{5}{*}{ 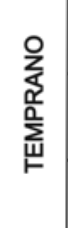 } & \multirow{2}{*}{ EMSIANO } & annulatus- & R. clandestinus & & & $\begin{array}{l}\text { Evitia sommeril- } \\
\text { Emph. annulatus }\end{array}$ & \\
\hline & & & $\begin{array}{c}\text { sextanti } \\
\text { polygonalis- }\end{array}$ & & & \multirow{4}{*}{ D. emsiensis } & & \\
\hline & & PRAGHIANO & emslensis & & & & & \\
\hline & & & $\begin{array}{c}\text { breconensis- } \\
\text { zavallatus }\end{array}$ & & & & & \\
\hline & & LOCHKOVIANO & $\begin{array}{l}\text { micromatus- } \\
\text { newportensis }\end{array}$ & & & & $\begin{array}{l}\text { Schisocystia- } \\
\text { Dictyotriletes }\end{array}$ & \\
\hline
\end{tabular}

FIG. texto 6. Cuadro de correlación de las asociaciones aquí estudiadas (F) con otras biozonas del Devónico y Carbonífero Temprano de Europa Occidental y América del Norte (A), Rusia (B), Australia (C), Brasil (D), Bolivia (E). Referencias: A: Richardson, McGregor (1986), Higgs et al. (1988); B: Avchimovitch et al. (1988, 1993); C: Playford (1985, 1991); Young (1996); D: Melo, Loboziak (2003); E: Suárez Soruco, Lobo Boneta (1983); Limachi et al. (1996). Z: hiato.

Cabe señalar que la aparición diacrónica de algunas de las especies de esporas antes citadas entre las asociaciones de la franja paleoecuatorial (inclu- yendo el norte de Brasil) y las del sur de Bolivia, podría deberse a procesos de migración entre ambas regiones. 
Con respecto a los quitinozoarios, Grahn (2002) recuperó de la parte basal de la Formación Huamampampa en la sección de Balapuca, los siguientes quitinozoarios: Lagenochitina sp., Ancyrochitina langei Sommer y van Boekel, Ramochitina sp., Ancyrochitina sp., y Ancyrochitina 123 Lange. En la Formación Los Monos el mismo autor halló las siguientes especies: Ancyrochitina langei Sommer y Boekel, Ancyrochitina cf. 124 Lange, Ramochitina sp., Ancyrochitina 24 Lange, Ancyrochitina 123 Lange, Ramochitina 122 Lange, Ramochitina ramosi Sommer y Boekel, Ramochitina boliviensis Grahn, Ancyrochitina sp. y Hoegisphaera sp. De ellas sólo dos especies son comparables a los especímenes aquí ilustrados, uno en la lámina $2 \mathrm{~L}, \tilde{\mathrm{N}}$, $\mathrm{Q}$ correspondientes al BAFC-PI 1283 (A1), semejantes a la especie Ancyrochitina sp. ilustrada por Grahn (2002, Fig. texto $5 \mathrm{H}$ ); en tanto el espécimen ilustrado en la lámina $5 \mathrm{~B}$ identificado en el BAFC-PI 1270 (A2) es muy semejante a Ancyrochitina sp. ilustrado también por Grahn (2002, Lám. 1C). Sibien el autor reconoce que en la literatura la Formación Los Monos es asignada del Eifeliano tardío al Frasniano temprano, la presencia de Ramochitina boliviensis restringida al Givetiano temprano en el perfil de Balapuca, Ancyrochitina postdesmea Grahn y Ancyrochitina multibrachiata Grahn y Melo 2004 (=Ancyrochitina 24 Lange), comunes en el Givetiano temprano, Ancyrochitina cf. A. morzadeci Paris del Givetiano temprano a medio y Ancyrochitina taouratinensis Boumendjel del Givetiano temprano tardío al Givetiano tardío, en la Cuenca Paraná, le sugieren una edad givetiana temprano a Frasniano temprano para la Formación Los Monos.

Por otra parte, Grahn y Melo (2004) redefinieron Ancyrochitina cf. 124 Lange como Ramochitina sp. A, y según el esquema de biozonación presentado por Grahn (2005) para el oeste de Gondwana, esta especie sería exclusiva de la Biozona Alpenachitina eisenacki del Eifeliano tardío de la Cuenca Amazonas, además de registrarse en la Formación Huamampampa en las secciones de Sobo-Sobo y Tarabuco. En tanto no menciona su presencia en la Formación Los Monos en Balapuca.

Debido a que los quitinozoarios aquí ilustrados estrechamente comparables con los ilustrados por Grahn (2002), no son citados en el esquema de distribuciones estratigráficas presentado por Grahn (2005), sumado a la falta de otras especies de quitinozoarios en las asociaciones aqui estudiadas y de otros grupos palinológicos (esporas, acritarcas)en las asociaciones de Grahn (2002), y al hecho que este autor no presentó un perfil estratigráfico de Balapuca, no es posible establecer una correspondencia más precisa entre los dos muestreos palinológicos. Las diferencias en la edad relativa asignada para la unidad en cuestión pueden deberse principalmente al uso de diferentes grupos palinológicos en forma independiente, aunque no se descarta la posibilidad de haber obtenido niveles fértiles no equivalentes estratigráficamente.

\section{AGRADECIMIENTOS}

La autora agradece la asistencia estratigráfica en el campo al Lic. E. Gallardo (Universidad Nacional de Salta, Argentina) en la campaña de 1998 y al Lic. L. Albariño (exPluspetrol S.A.)y al Dr. J. Oller (Pluspetrol S.A.) en la de 2000. A los Dres. C. Azcuy (Facultad de Ciencias Exactas y Naturales, Universidad Buenos Aires, Argentina) y H. Carrizo (Instituto Miguel Lillo, Tucumán, Argentina), por formar parte del equipo en dichas campañas, las cuales se realizaron en el primer caso en el marco de mi Tesis Doctoral y en el otro caso, permitió la realización de este trabajo en el marco de una Beca Postdoctoral (CONICET). A mi hemana Paula, por su generosa ayuda para concretar esta contribución en un momento especial de mi vida. Al Lic. G. Holfeltz, técnico a cargo del Laboratorio de Palinoestratigrafía y Paleobotánica (F.C.E.N., UBA), por el procesamiento palinológico de las muestras. Finalmente, un agradecimiento especial a los árbitros Dres. C. Rubinstein, J.A. Salfity y T. Sempere, por sus positivas apreciaciones sobre el manuscrito y sus comentarios a partir de los cuales he podido mejorarlo. Este trabajo ha sido financiado con fondos de los Proyectos UBACYT X 136, PICT R 00313/03 AGENCIA y PIP 5518 CONICET. 


\section{REFERENCIAS}

Aceñolaza, F.G.; Aceñolaza, G.; García, G. 2000. El Silúrico-Devónico del Noroeste Argentino. In Geología Argentina (Caminos, R.; coordinador-editor). Instituto de Geología y Recursos Minerales, Anales 29 (9): 205-214. Buenos Aires.

Ahlfeld, F.; Branisa, L. 1960. Geología de Bolivia. Editorial Don Bosco: 215 p. La Paz.

Albariño, L.; Dalenz Farjat, A.; Álvarez, L.; Hernández, R.; Pérez Leyton, M. 2002. Las Secuencias Sedimentarias del Devónico en el Subandino Sur y el Chaco. Bolivia y Argentina. In Congreso de Exploración y Desarrollo de Hidrocarburos, No. 5, CD Trabajos Técnicos. Mar del Plata.

Allen, K.C. 1965. Lower and Middle Devonian spores of North and Central Vestspitsbergen. Palaeontology 8: 687-748.

Álvarez, L.A.; Dalenz Farjat, A.; Hernández, R.M.; Albariño, L.M. 2003. Integración de facies y biofacies en un análisis secuencial en plataformas clásticas devónicas del sur de Bolivia y noroeste Argentino. Revista de la Asociación Argentina de Sedimentología 10 (2): 103121.

Amenábar, C.R. 2006. Significado estratigráfico de palinomorfos retrabajados en la Formación Malimán (Viseano) en la Sierra del Volcán, Provincia de San Juan, Argentina. Resultados preliminares. Revista Brasileira de Paleontologia 9 (1): 21-32.

Amenábar, C.R.; di Pasquo, M.M.; Carrizo, H.; Azcuy, C.L. 2006. Palynology of the Chigua and Maliman Formations in the Sierra del Volcán, San Juan province, Argentina. Part I. Palaeomicroplankton and acavate smooth and ornamented spores. Ameghiniana $\mathbf{4 3}$ (2): 339-375.

Amenábar, C.R.; di Pasquo, M.; Carrizo, H.; Azcuy, C. L. En prensa. Palynology of the Chigua and Malimán Formations in the Sierra del Volcán, San Juan province, Argentina. Part 2. Cavate and pseudosaccate spores. Ameghiniana.

Anzulovich, F.; Sciamanna, S.; Reinante, S. 2005. Análisis estratigráfico y modelado de los sistemas petroleros en las Cuencas de Ucayali y Madre de Dios (Perú). INGEPET (EXPR-2-FA-34) 5: 1-13.

Aramayo Flores, F.R. 1989. El cinturón plegado y sobrecorrido del norte argentino. Boletín de Informaciones Petroleras, Tercera Época 17: 2-16.

Avchimovitch, V.I.; Byvscheva, T.V.; Higgs, K.; Streel, M.; Umnova, V.T. 1988. Miospore systematics and stratigraphic correlation of Devonian-Carboniferous Boundary deposits in the European part of the USSR and western Europe. Courier Forschungs-Institut Senckenberg 100: 169-191.

Avchimovitch, V.I.; Tchibrikova, E.V.; Obukhovskaya, T.G.; Nazarenko, A.M.; Umnova, V.T.; Raskatova, L.G.; Mantsurova, V.N.; Loboziak, S.; Streel, M.
1993. Middle and Upper Devonian miospore zonation of Eastern Europe. Bulletin des Centres de Recherches Exploration-Production Elf-Aquitaine 17: 79-147.

Ayavirí, A. 1972. El Sistema Carbónico en el sureste boliviano. Anales de la Academia Brasileira de Ciências (suplemento) 44: 51-60.

Azcuy, C.L.; Caminos, R. 1988. Características paleogeográficas y diastróficas de algunas cuencas neopaleozoicas de América del Sur: una reseña. Boletín de la Sociedad Geológica del Perú 78: 203-224.

Azcuy, C.L.; di Pasquo, M.M. 2000. Carbonífero y Pérmico de las Sierras Subandinas, Cordillera Oriental y Puna. In Geología Argentina (Caminos, R.; coordinador-editor). Instituto de Geología y Recursos Minerales, Anales 29 (11): 239-260. Buenos Aires.

Azcuy, C.L.; di Pasquo, M.M. 2005. Early Carboniferous palynoflora of the Ambo Formation, Pongo de Mainique, Perú. Review of Palaeobotany and Palynology 134 (34): 153-184.

Azcuy, C.L.; di Pasquo, M.M. 2006. Additional systematic information on the Early Carboniferous palynomorphs from the Ambo Formation, Pongo de Mainique, Perú Revista Brasileira de Paleontología 9 (1): 41-52.

Azcuy, C.L.; Laffitte, G. 1981. Palinología de la Cuenca Noroeste Argentina. I. Características de las asociaciones carbónicas: problemas e interpretación. In Congreso Geológico Argentino, No. 8, Actas 4: 823-838. San Luis.

Balme, B.E. 1988. Miospores from Late Devonian (early Frasnian) strata, Carnarvon Basin, Western Australia. Palaeöntographica Abteilung B 209: 109-166.

Becker, G.; Bless, M.J.; Streel, M.; Thorez, J. 1974. Palynology and ostracode distribution in the Upper Devonian and basal Dinantian of Belgium and their dependence on sedimentary facies. Mededelingen Rijks Geologische Dienst, Nieuwe Serie 25: 9-99.

Blieck, A.; Gagnier, P.Y.; Bigey, E.P.; Edgecombe, G.D.; Janvier, P.; Loboziak, S.; Racheboeuf, P.R.; Sempere T.; Steemans, P. 1996. New Devonian fossil localities in Bolivia. Journal of South American Earth Sciences 9: 295-308.

Braman, D.R.; Hills, L.V. 1992. Upper Devonian and Lower Carboniferous miospores, western District of Mackenzie and Yukon Territory, Canada. Palaeontographica Canadiana 8: 1-97.

Burjack, M.I.A.; Loboziak, S.; Streel, M. 1987. Quelques données nouvelles sur les miospores dévoniennes du bassin du Paraná (Brésil). Bulletin of Sciences Géologiques 40: 381-391.

Daemon, R.F.; Quadros, L.P.; Silva, L.C. 1967. Devonian palynology and biostratigraphy of the Paraná Basin. In Problems in Brazilian Devonian Geology (Bigarella, J.J.; editor). Boletim Paranaense de Geociências 21- 
22: 99-132.

Dalenz Farjat, A.; Alvarez, L.A.; Hernández, R.M.; Albariño, L.M. 2002. Cuenca Siluro-Devónica del Sur de Bolivia y del Noroeste Argentino: algunas interpretaciones. In Congreso de Exploración y Desarrollo de Hidrocarburos, No. 5, CD ROM Trabajos Técnicos. Mar del Plata.

Davydov, V.; Wardlaw, B.R.; Gradstein, F.M. 2004. The Carboniferous Period. In A Geologic Time Scale (Gradstein, F.M.; Ogg, J.G.; Smith, A.G.; editors). Cambridge University Press 15: 222-248.

Dettmann, M. 1963. Upper microfloras from south-eastern Australia. Proceedings of the Royal Society of Victoria 77: 1-148.

Deunff, J. 1971. Le genre Polyedryxium Deunff. Révision et observations. Microfossiles organiques du Paleozoique. 3 Achritarches. Commission Internationale de Microflore du Paleozoique, Centre National de la Recherche Scientifique: 7-49. Paris.

Díaz Martínez, E. 1999. Estratigrafía y paleogeografía del Paleozoico Superior del norte de los Andes Centrales (Bolivia y sur del Perú). In Volumen Jubilar '75 Aniversario Sociedad Geológica del Perú' (Macharé, J.; Benavides, V.; Rosas, S.; editores). Boletín de la Sociedad Geológica del Perú 5: 19-26.

Díaz Martínez, E.; Vavrdová, M.; Bek, J.; Isaacson, P.E. 1999. Late Devonian (Famennian) glaciation in western Gondwana: evidence from the Central Andes. Abhandlungen der Geologischen Bundesanstalt 54: 213-237.

Dino, R. 1999. Palynostratigraphy of the Silurian and Devonian sequence of the Paraná Basin, Brazil. In Ordovician-Devonian Palynostratigraphy in Western Gondwana: Update, Problems and Perspectives (Rodrigues, M.A.C.; Pereira, E.; editors). Universidade do Estado do Rio de Janeiro, Facultad de Geología: 27-61. Río de Janeiro.

di Pasquo, M.M. 1999. Palinología, bioestratigrafía y correlación de las asociaciones presentes en los Grupos Macharetí y Mandiyutí, Neopaleozoico de la Cuenca Tarija, Provincia de Salta, Argentina. Ph.D. Thesis (Inédito), Facultad de Ciencias Exactas y Naturales, Universidad de Buenos Aires: 480 p.

di Pasquo, M. 2002. The Crassispora kosankeiCystoptychus azcuyi Palynozone from the Upper Carboniferous Tupambi Formation, Tarija basin, northern Argentine. Review of Palaeobotany and Palynology 118: 47-75

di Pasquo, M.M. 2003. Avances sobre palinología, bioestratigrafía y correlación de las asociaciones presentes en los Grupos Macharetí y Mandiyutí, Neopaleozoico de la Cuenca Tarija, provincia de Salta, Argentina. Ameghiniana 40 (1): 3-32.

di Pasquo, M.M. 2005. Resultados palinológicos preliminares de estratos del Devónico y Carbonífero en el perfil de Balapuca, sur de Bolivia. In Congreso Geológico Argentino, No. 16, Actas 4: 293-298. La Plata. di Pasquo, M.M.; Azcuy, C.L. 1997. Palinomorfos retra- bajados en el Carbonífero Tardío de la Cuenca Tarija (Argentina): su aplicación a la datación de eventos diastróficos. Revista Universidade Guarulhos, Série Geociências (No. especial) 2: 28-42.

di Pasquo M.M.; Azcuy C.L. 1999. Paleontología, paleoclima y correlación de estratos carboníferos en la provincia de Salta sobre la base de palinomorfos. In Congreso Geológico Argentino, No. 14, Relatorio 1: 254-260. Salta.

Ghavidel-Syooki, M. 2003. Palynostratigraphy of Devonian sediments in the Zagros Basin, southern Iran. Review of Palaeobotany and Palynology 127: 241-268.

Grahn, Y. 2002. Upper Silurian and Devonian chitinozoa from central and southern Bolivia, central Andes. Journal of South American Earth Sciences 15: 315-326.

Grahn, Y. 2005. Devonian chitinozoan biozones of Western Gondwana. Acta Geologica Polonica 55 (3): 211-227.

Grahn, Y.; Gutiérrez, P.R. 2001. Silurian and Middle Devonian Chitinozoa from the Zapla and Santa Bárbara Ranges, Tarija Basin, northwestern Argentina. Ameghiniana 38: 35-50.

Grahn, Y.; Melo, J.H.G. 2004. Integrated Middle Devonian chitinozoan and miospore zonation of the Amazonas Basin, northern Brazil. Revue de micropaléontologie 47: 71-85.

Higgs, K.T.; Clayton, G.; Keegan, J.B. 1988. Stratigraphy and systematic palynology of the Tournaisian rocks of Ireland. Geological Survey of Ireland, Special Paper 7: 1-93.

House, M.R.; Gradstein, F.M. 2004. The Devonian Period. In A Geologic Time Scale (Gradstein, F.M.; Ogg, J.G.; Smith, A.G.; editors). Cambridge University Press 14: 202-221.

lannuzzi, R.; Pfefferkorn, H.W. 2002. A pre-glacial warmtemperate floral belt in Gondwana (late Visean, Early Carboniferous). Palaios 17: 571-590.

Isaacson, P.E.; Hladil, J.; Shen, J.W.; Kalvoda, J.; Grader, G. 1999. Late Devonian Famennian Glaciation in South America and Marine Offlap on other Continents. In North Gondwana: Mid-Paleozoic Terranes, Stratigraphy and Biota (Feist, R.; Talent, J.A.; Daurer, A.; editors). Abhandlungen der Geologischen Bundesanstalt 54: 239-257.

Isbell, J.L.; Miller, M.F.; Wolfe, K.L.; Lenaker, P.A. 2003. Timing of late Paleozoic glaciation in Gondwana: was glaciation responsible for the development of northern hemisphere cyclothems? In Extreme depositional environments: Mega end members in geologic time (Chan, M.A.; Archer, A.W., editors). Geological Society of America, Special Paper 370:1-20.

Jäger, H. 2002. Palynology of the Lower Carboniferous (Mississippian) Kammquartzite Formation in the Rhenohercynian Zone, Germany. Senckenbergiana lethaea 82 (2): 609-637.

Jaillard, E.; Hérail, G.; Monfret, T.; Díaz Martínez, E.; Baby, P.; Lavenu, A.; Dumont, J.F. 2000. Tectonic evolution of the Andes of Ecuador, Perú, Bolivia and 
northernmost Chile. In Tectonic Evolution of South America (Cordani, U.G.; Milani, E.J.; Thomaz Filho, A.; Campos, D.A.; editors). Sociedade Brasileira de Geología: 481-559. Rio de Janeiro.

Kimyai, A. 1983. Palaeozoic microphytoplankton from South America. Revista Española de Micropaleontología 15 (3): 415-426.

Lanninger, E.P. 1968. Sporen-Gesellshcften aus dem Ems der SW-Eifel (Rheinischés schiefegebirge). Palaeöntographica, Abteilung B 122: 95-170.

Le Hérissé, A.; Rubinstein, C.; Steemans, P. 1997. Lower Devonian Palynomorphs from the Talacasto Formation, Cerro del Fuerte Section, San Juan Precordillera, Argentina. In Acritarcha in Praha (Fatka, O.; Servais, T.; editors). Acta Universitatis Carolinae Geologica 40: 497-515.

Le Hérissé, A.; Servais, T.; Wicander, R. 2000. Devonian acritarchs and related forms. Courier Forschungsinstitut Senckenberg 220: 195-205.

Limachi, R.; Goitia, V.H.; Sarmiento, D.; Arispe, O.; Montecinos, R.; Diaz Martínez, E.; Dalenz Farjat, A.; Liachenco, N.; Pérez Leyton, M.; Aguilera, E. 1996. Estratigrafía, Geoquímica, Correlaciones, Ambientes Sedimentarios y Bioestratigrafía del Silúrico-Devónico de Bolivia. In Congreso Geológico de Bolivia, No. 12, Memorias: 183-197. Tarija.

Lobo Boneta, J. 1975. Sobre algunos palinomorfos del Devónico Superior y Carbónico Inferior de la zona subandina sur de Bolivia. Revista Técnica Yacimientos Petrolíferos Fiscales Bolivianos (Anales de la IV Convención Nacional de Geología, tomo 1) 4 (3): 159-176.

Lobo Boneta, J. 1989. El límite Devónico-Carbonífero en el Subandino Sur de Bolivia. Revista Técnica de Yacimientos Petrolíferos Fiscales Bolivianos 10 (3-4): 213-217.

Loboziak, S.; Melo, J.H.G. 2000. Miospore events from late Early to Late Devonian strata of Western Gondwana. Geobios 33: 399-407.

Loboziak, S.; Melo, J.H.G. 2002. Devonian miospore successions of Western Gondwana: update and correlation with Southern Euroamerican miospore zones. Review of Palaeobotany and Palynology 121: 133-148.

Loboziak, S.; Streel, M. 1981. Miospores in middle-upper Frasnian to Famennian sediments partly dated by conodonts (Boulonnais), France. Review of Palaeobotany and Palynology 34: 49-66.

Loboziak, S.; Streel, M. 1989. Middle-Upper Devonian miospores from the Ghadamis Basin (Tunisia-Libya): systematics and stratigraphy. Review of Palaeobotany and Palynology 58: 173-196.

Loboziak, S.; Streel, M. 1995. West Gondwanian aspects of the Middle and Upper Devonian miospore zonation in North Africa and Brazil. Review of Palaeobotany and Palynology 86: 147-155.

Loboziak, S.; Streel, M.; Burjack, M.I.A. 1988. Miospores du Dévonien moyen et supérieur du Bassin du Paraná, Brésil: systématique et stratigraphie. Bulletin des Sciences Géologiques 41: 351-377.

Loboziak, S.; Streel, M.; Weddige, K. 1991a. Miospores, the Lemurata and Triangulatus levels and their faunal indices near the Eifelian/Givetian boundary in the Eifel. Annales de la Société Géologique de Belgique 113: 299-313.

Loboziak, S.; Streel, M.; Caputo, M.V.; Melo, J.H.G. 1991 b. Evidence of West European-defined miospore zones in the uppermost Devonian and Lower Carboniferous of the Amazonas Basin (Brazil). Geobios 24: 5-11.

Loboziak, S.; Streel, M.; Caputo, M.V.; Melo, J.H.G. 1992. Middle Devonian to Lower Carboniferous miospore stratigraphy in the central Parnaiba Basin (Brazil). Annales de la Société Géologique de Belgique 115: 215-226.

Loboziak, S.; Melo, J.H.G.; Matsuda, N.S.; Quadros, L.P. 1997 a. Miospore biostratigraphy of the type Barreirinha Formation (Curuá Group, Upper Devonian) in the Tapajós River area, Amazon Basin, North Brazil. Bulletin des Centres de Recherches Exploration-Production Elf-Aquitaine 21: 187-205.

Loboziak, S.; Melo, J.H.G.; Quadros, L.P.; Streel, M. 1997 b. Palynological evaluation of the Famennian Protosalvinia (Foerstia) Zone in the Amazon Basin, Northern Brazil: a preliminary study. Review of Palaeobotany and Palynology 96: 31-45.

Loboziak, S.; Melo, J.H.G.; Streel, M. 1998. Reassessment of Viséan miospore biostratigraphy in the Amazon Basin, northern Brazil. Review of Palaeobotany and Palynology 104: 143-155.

Loboziak, S.; Streel, M.; Melo, J.H.G. 1999. Grandispora (al. Contagisporites) permulta (Daemon, 1974) Loboziak, Streel et Melo, comb. nov., a senior synonym of Grandispora riegelii Loboziak et Streel, 1989. Nomenclature and stratigraphic distribution. Review of Palaeobotany and Palynology 106: 97-102.

Loboziak, S.; Melo, J.H.G.; Streel, M. 2000. Latest Devonian and Early Carboniferous palynostratigraphy of Northern Brazil and North Africa -a proposed integration of western European and Gondwanan miospore biozonations. Bulletin des Centres de Recherches Exploration-Production ElfAquitaine 22: 241-259.

Mather, K.F. 1922. Front ranges of the Andes between Santa Cruz and Embarcación. Bulletin of Geological Society of America 33: 703-764.

McGregor, D.C. 1961. Spores with proximal radial pattern from the Devonian of Canada. Geological Survey of Canada, Bulletin 76: 1-11.

McGregor, D.C. 1973. Lower and Middle Devonian spores of eastern Gaspé, Canada. I. Systematics. Palaeöntographica, Abteilung B 142 (1-3): 1-77.

McGregor, D.C. 1979. Devonian miospores of North America. Palynology 3: 31-52.

McGregor, D.C. 1984. Late Silurian and Devonian spores from Bolivia. Academia Nacional de Ciencias de Córdoba, Miscelánea 69: 1-43. 
McGregor, D.C. 1996. Spores of the Escuminac Formation. In Devonian fishes and plants of Miguasha, Quebec, Canada (Schultze, H.P.; Cloutier, R.; editors). Verlag Dr. Friedrich Pfeil: 91-102. München, Alemania.

McGregor, D.C.; Camfield, M. 1976. Upper Silurian? To Middle Devonian spores of the Moose river basin, Ontario. Geological Survey of Canada, Bulletin 263: 1-63.

McGregor, D.C.; Camfield, M. 1982. Middle Devonian miospores from the Cape de Bray, Weatherall, and Hecla Bay Formations of northeastern Melville Island, Canadian Arctic. Geological Survey of Canada, Bulletin 348: 1-105.

Melo, J.H.G. 2000. Palynological evaluation and correlation of some Silurian-Devonian sections of southern Bolivia. In Congreso Geológico de Bolivia, No. 14, Memorias: 136-141. La Paz.

Melo, J.H.G.; Loboziak, S. 2003. Devonian-Early Carboniferous miospore biostratigraphy of the Amazon Basin, Northern Brazil. Review of Palaeobotany and Palynology 124: 131-202.

Melo, J.H.G.; Loboziak, S.; Streel, M. 1999. Latest Devonian to early Late Carboniferous biostratigraphy of northern Brazil: an update. Bulletin des Centres de Recherches Exploration-Production Elf-Aquitaine 22: 13-33.

Menéndez, C.A.; Pöthe de Baldis, E.D. 1967. Devonian Spores from Paraguay. Review of Palaeobotany and Palynology 1: 161-172.

Miranda, A.P.; Souza Cruz, C.E.; Oller, J. 2000. Sequence stratigraphy of the Late Silurian-Devonian Subandean Basin, Southern Bolivia and Northern Argentina. In Congreso Boliviano de Geología, No. 14, Memorias: 46-50. La Paz.

Moreau-Benoit, A. 1979. Les spores du Dévonien de Libye, 1ère. partie. Centre National de la Recherche Scientifique, Paris. Cahiers de Micropaléontologie 4: 3-58.

Moreau-Benoit, A. 1980. Les spores du Dévonien de Libye, 2ème. partie. Centre National de la Recherche Scientifique, Paris. Cahiers de Micropaléontologie 1: 3-53.

Moreau-Benoit, A. 1989. Les spores du Dévonien moyen et supérieur de Libye occidentale: compléments, systématique, répartition stratigraphique. Centre National de la Recherche Scientifique, Paris. Cahiers de Micropaléontologie 4 (1): 5-32.

Ottone, E.G. 1996. Devonian palynomorphs from the Los Monos Formation, Tarija Basin, Argentina. Palynology 20: 101-151.

Ottone, E.G.; Rossello, E.A. 1996. Palinomorfos devónicos de la Formación Tequeje, Angosto del Beu, Bolivia. Ameghiniana 33 (4): 443-452.

Owens, B. 1971. Miospores from the Middle and Early Upper Devonian rocks of the Western Queen Elizabeth Islands, Arctic Archipielago. Geological Survey of Canada, Paper 70 (38): 1-157.

Padula, E.L.; Reyes, F.C. 1958. Contribución al léxico estratigráfico de las Sierras Subandinas, Bolivia. Yacimientos Petrolíferos Fiscales Bolivianos, Boletín Técnico 1 (1): 9-70.

Paris, F.; Richardson, J.B.; Riegel, W.; Streel, M.; Vanguestaine, M. 1985. Devonian (Emsian-Famennian) palynomorphs. Journal of Micropaleontology 4 (1): 49-82.

Pérez Leyton, M. 1990. Palynomorphes du Devonien Moyen et Superieur de la Coupe de Bermejo-La Angostura (Sud-Est de la Bolivie). Master Dissertation (Unpublished), Faculté des Sciences, Université de Liège: $156 \mathrm{p}$. Belgium.

Pérez Leyton, M. 1991. Miospores du Devonien Moyen et Superior de la coupe de Bermejo-La Angostura (Sud-Est de la Bolivie). Annales de la Société Géologique de Belgique 113 (2): 373-389.

Playford, G. 1983. The Devonian miospores genus Geminospora Balme 1962: a reappraisal based upon topotypic G. lemurata (type species). Association Australasian Paleontology, Memoir 1: 311-325.

Playford, G. 1985. Palynology of the Australian Lower Carboniferous: a review. In International Congress on Stratigraphy and Geology of Carboniferous, No. 10, Comptes Rendus 4: 247-265. Madrid.

Playford, G. 1991. Australian Lower Carboniferous miospores relevant to extra-Gondwanic correlations: and evaluation. Courier Forschungs-Institut Senckenberg 130: 85-125.

Playford, G. 1993. Miospores and organic walled microphytoplankton characteristic of strata contiguous with the Devonian-Carboniferous boundary. In Congrès International de la Stratigraphie et Géologie du Carbonifère et Permien, No. 12, Comptes Rendus 1: 127-160. Buenos Aires.

Playford, G.; McGregor, D.C. 1993. Miospores and organicwalled microphytoplankton of Devonian-Carboniferous boundary beds (Bakken Formation), Southern Saskatchewan: a systematic and stratigraphic appraisal. Geological Survey of Canada, Bulletin 445: 1-107.

Potonié, R. 1956. Synopsis der Gattungen der Sporae Dispersae. I vol. Beihefte zum geologischen Jahrbuch 23: 1-103.

Potonié, R. 1970. Synopsis der Gattungen der Sporae dispersae. V.Teil: Nachtrage zuallen Gruppen(Turmae). Beihefte zum geologischen Jahrbuch 87: 1-222.

Potonié, R.; Kremp, G. 1954. Die Gattungen der Paläozoischen sporae dispersae und ihre Stratigraphie. Beihefte zum geologischen Jahrbuch 69: 111-194.

Potonié, R.; Kremp, G. 1955. Die Sporae dispersae des Ruhrkarbons, ihre Morphographie und Stratigraphie mit Ausblicken auf Arten anderer Gebiete und Zeitabschnitte, 1. Palaeöntographica, Abteilung B 98: 1-136.

Quadros, L.P. 1999. Silurian-Devonian acritarch assemblages from Paraná Basin: an update and correlation with northern Brazilian basins. In Ordovician - Devonian Palynostratigraphy in Western Gondwana: Update, Problems and Perspectives (Rodrigues, 
M.A.C.; Pereira, E.; editores). Universidade do Estado do Rio de Janeiro, Facultad de Geología: 105-145. Río de Janeiro.

Racheboeuf, P.; Le Hérissé, A.; Paris, F.; Babin, C.; Guillocheau, F.; Truyols-Massoni, M.; Suárez-Soruco, R. 1993. Le Dévonien de Bolivie: biostratigraphie et chronostratigraphie. Comptes Rendus de l'Academie de Sciences de Paris 317 (2): 795-802.

Ramos, V. 2000. Las provincias geológicas del territorio argentino. In Geología Argentina (Caminos, R.; Coordinador-editor). Instituto de Geología y Recursos Minerales, Anales 29 (3): 41-96. Buenos Aires.

Ramos, V. 2004. Cuyania, an Exotic Block to Gondwana: Review of a Historical Success and the Present Problems. Gondwana Research 7 (4): 1009-1026.

Ramos, V.; Jordan, T.; Allmendinger, R.; Kay, S.; Cortés, J.; Palma, M. 1984. Chilenia: un terreno alóctono en la evolución paleozoica de los Andes Centrales. In Congreso Geológico Argentino, No. 9, Actas 2: 84-106. San Carlos de Bariloche.

Reyes, F.C. 1972. On the Carboniferous and Permian of Bolivia and Northwestern Argentina. Anales de la Academia Brasileira de Ciências (Supl.) 4: 261-277.

Richardson, J.B. 1965. Middle Old Red Sandstone spore assemblages from the Orcadian Basin north-east Scotland. Palaeontology 7 (4): 559-605.

Richardson, J.B.; Lister, T.R. 1969. Upper Silurian and Lower Devonian spore assemblages from the Welsh Borderland and South Wales. Palaeontology 12: 201-252.

Richardson, J.B.; McGregor, D.C. 1986. Silurian and Devonian spore zones of the Old Red Sandstone continent and adjacent regions. Geological Survey of Canada, Bulletin 364: 1-79.

Riegel, W. 1968. Die Mitteldevon-Flora von Lindlar (Rheinland). 2. Sporae dispersae. Palaeöntographica, Abteilung B 123: 76-96.

Rodrigues, R.; Loboziak, S.; Melo, J.H.G.; Alves, D.B. 1995. Geochemical characterization and miospore biochronostratigraphy of the Frasnian anoxic event in the Parnaíba Basin, northeast Brazil. Bulletin des Centres de Recherches Exploration-Production ElfAquitaine 19: 319-327.

Rubinstein, C.V. 1999. Primer registro palinológico de la Formación Punta Negra (Devónico Medio-Superior), de la Precordillera de San Juan, Argentina. In Simposio Argentino de Paleobotánica y Palinología, No. 10. Asociación Paleontológica Argentina, Publicación Especial 6: 13-18. Buenos Aires

Rubinstein, C.V.; Melo, J.H.G.; Steemans, P. 2005. Lochkovian (earliest Devonian) miospores from the Solimões Basin, northwestern Brazil. Review of Palaeobotany and Palynology 133: 91-113.

Salfity, J.A. 1980. Desarrollo paleogeográfico del Paleozoico inferior del Noroeste Argentino. In Reunión Anual Proyecto 44 IGCP 'Lower Paleozoic of South America': 7. Lima.

Salfity, J.A.; Azcuy, C.L.; López Gamundi, O.; Valencio, D.A.; Vilas, J.F. 1987. Cuenca Tarija. In El Sistema
Carbonífero en la República Argentina (Archangelsky, S.; editor). Academia Nacional de Ciencias 2: 15-40. Córdoba.

Salfity, J.A.; Monaldi, C.R.; Guidi, F.; Salas, R.J. 1998. Mapa Geológico de la Provincia de Salta. Secretaría de Industria, Comercio y Minería, Servicio Geológico Minero Argentino, Instituto de Geología y Recursos Minerales (Escala 1:500.000). Buenos Aires.

Schulz, A.; Santiago, M.; Hernández, R.; Galli, C.; Álvarez, L.; del Papa, C. 1999. Modelo estratigráfico del Carbonífero en el sector sur de la cuenca de Tarija. In Congreso de Exploración y Desarrollo de Hidrocarburos, No. 4, Actas 2: 695-711. Mar del Plata.

Sempere, T. 1995. Phanerozoic Evolution of Bolivia and adjacent regions. In Petroleum basins of South America (Tankard, A.J.; Suárez S., R.; Welsink, H.J.; editores). American Association of Petroleum Geologists, Memoir 62: 207-230. Tulsa.

Sempere, T. 2004. Las 'fases tectónicas' en los Andes Centrales: Esplendor y decadencia de un paradigma geológico. In Nuevas contribuciones del IRD y sus contrapartes al conocimiento geológico del sur del Perú (Jacay, J.; Sempere, T.; editores). Sociedad Geológica del Perú, Publicación Especial 5: 203-216. Lima.

Smith, A.H.V.; Butterworth, M.A. 1967. Miospores in the coal sems of the Carboniferous of Great Britain. The Palaeontological Association, Special Paper in Palaeontology 1: 1-324.

Staplin, F.L. 1960. Upper Mississippian plant spores from the Golata Formation, Alberta, Canada. Palaeöntographica, Abteilung B 107: 1-40.

Starck, D. 1995. Silurian-Jurassic Stratigraphy and Basin Evolution of Northwestern Argentina. In Petroleum basins of South America (Tankard, A.J.; Suárez S., R.; Welsink, H.J.; editors). American Association of Petroleum Geologists, Memoir 62: 251-267. Tulsa.

Starck, D. 1999. Los sistemas petroleros de la Cuenca de Tarija. In Congreso de Exploración y desarrollo de Hidrocarburos, No. 4, Actas 1: 63-82. Mar del Plata.

Starck, D.; Gallardo, E.; Schulz, A. 1993a. Neopaleozoic stratigraphy of the Sierras Subandinas Occidentales and Cordillera Oriental, Argentina. In International Congress of Carboniferous-Permian, No. 12, Comptes Rendus 2: 353-372. Buenos Aires.

Starck, D.; Gallardo, E.; Schulz, A. 1993b. The preCarboniferous unconformity in the Argentine portion of the Tarija Basin. In International Congress of Carboniferous-Permian, No. 12, Comptes Rendus 2: 373-384. Buenos Aires.

Starck, D.; Constantini, L.; Schulz, A. 2002. Análisis de algunos aspectos geométricos y evolutivos de las estructuras de la faja plegada subandina del norte de Argentina y el sur de Bolivia. In Congreso de Exploración y Desarrollo de Hidrocarburos, No. 5, Proceedings. CD-ROM, Mar del Plata.

Steemans, P. 1989. Etude Palynostratigraphique du Dévonien Inférieur dans l'ouest de l'Europe. Professional Paper. Mémoires Explicatifs pour les 
Cartes Géologiques and Minières de la Belgique, Service Géologique de Belgique 27: 1-453. Bruxelles.

Streel, M. 1964. Une association de spores du Givétien inférieur de la Vesdre, à Goe (Belgique). Annales Société Géologique de Belgique 87: 1-30.

Streel, M. 1967. Associations de spores du Dévonien inférieur belge et leur signification stratigraphique. Annales de la Sociètè Géologique de Belgique 90 (1): 11-54.

Streel, M.; Higgs, K.; Loboziak, S.; Riegel, W.; Steemans, P. 1987. Spore stratigraphy and correlation with faunas and floras in the type marine Devonian of the Ardenne-Rhenish regions. Review of Palaeobotany and Palynology 50: 211-229.

Streel, M.; Caputo, M.V.; Loboziak, S.; Melo, J.H.G. 2000. Late Frasnian-Famennian climates based on palynomorph analysis and the question of the Late Devonian glaciations. Earth-Sciences Reviews 52: 121-173.

Suárez Soruco, R. 1989. El ciclo Cordillerano (SilúricoCarbonífero inferior) en Bolivia y su relación con países limítrofes. Revista Técnica Yacimientos Petrolíferos Fiscales Bolivianos 10: 233-243.

Suárez Soruco, R. 2000. Compendio de Geología de Bolivia. Revista Técnica Yacimientos Petrolíferos Fiscales Bolivianos 18 (1-2): 1-213.

Suárez Soruco, R.; Díaz Martínez, E. 1996. Léxico Estratigráfico de Bolivia. Revista Técnica Yacimientos Petrolíferos Fiscales Bolivianos 17: 1-227.

Suárez Soruco, R.; Lobo Boneta, J. 1983. La fase compresiva Eohercínica en el sector oriental de la Cuenca Cordillerana de Bolivia. Revista Técnica Yacimientos Petrolíferos Fiscales Bolivianos 9: 189-202.

Suárez Soruco, R.; López Pugliessi, M. 1983. Formación Saipurú, nuevo nombre formacional para representar a los sedimentos superiores del Ciclo Cordillerano (Devónico superior-Carbónico inferior), Bolivia. Yacimientos Petrolíferos Fiscales Bolivianos, Revista Técnica 9: 209-213.

Tankard, A.J.; Uliana, M.A.; Welsink, H.J.; Ramos, V.A.; Turic, M.; França, A.B.; Milani, E.J.; Brito Neves, B.B.; Eyles, N.; Skarmeta, J.; Santa Ana, H.; Wiens, F.; Cirbián, M.; López Paulsen, O.; Germs, G.J.B.; De Wit, M.J.; Machacha, T.; McG. Miller, R. 1995. Structural and tectonic controls of basin evolution in southwestern Gondwana during the Phanerozoic. In Petroleum basins of South America (Tankard, A. J.; Suárez Soruco R.; Welsink, H. J.; editors). American Association Petroleum Geologists Foundation, Memoir 62: 552. Tulsa.

Tiwari, R.S.; Schaarschmidt, F. 1975. Palynological studies in the Lower and Middle Devonian of the Prüm Syncline, Eifel (Germany). Abhandlungen der Senckenber- gischen naturoforschenden Gesellschaft 534: 1-129.

Turnau, E. 1975. Microflora of the Famennian and Tournaisian deposits from boreholes of northern Poland. Acta Geologica Polonica 25: 505-528.

Turnau, E. 1978. Spore zonation of Uppermost Devonian and Lower Carboniferous deposits of western Pomerania. Mededelingen rijks geologische dienst 30: 1-35.

Turnau, E. 1986. Miospore stratigraphy of Middle Devonian deposits from western Pomerania. Review of Palaeobotany and Palynology 93: 107-125.

Turnau, E. 1996. Miospore stratigraphy of Middle Devonian deposits from Western Pomerania. Review of Palaeobotany and Palynology 93: 107-125.

Turnau, E.; Racki, G. 1999. Givetian palynostratigraphy and palynofacies: new data from the Bodzentyn Syncline (Holy Cross Mountains, central Poland). Review of Palaeobotany and Palynology 106: 237-271.

Utting, J. 1987. Palynology of the Lower Carboniferous Windsor Group and Windsor-Canso boundary beds of Nova Scotia, and their equivalents in Quebec, New Brunswick and Newfoundland. Geological Survey of Canada, Bulletin 374: 1-93.

Utting, J.; Giles, P.S. 2004. Biostratigraphical implications of new palynological data from the Mississippian of Newfoundland and Nova Scotia, Canada. Memoirs of the Association of Australasian Palaeontologists 29: $115-160$.

Utting, J.; Wielens, H. 1992. Organic petrology, thermal maturity, geology, and petroleum source rock potential of Lower Permian coal, Karoo Supersystem, Zambia. Energy Sources 14: 337-354.

Vavrdová, M.; Isaacson, P.E. 1999. Late Famennian phytogeographyc provincialism: Evidence for a limited separation of Gondwana and Laurentia. Abhandlungen der Geologischen Bundesanstalt 54: 453-463.

Vavrdová, M.; Bek, J.; Dufka, P.; Isaacson, P.E. 1996. Palynology of the Devonian (Lochkovian to Tournaisian) sequence, Madre de Dios Basin, northern Bolivia. Vestnik Ceskeho geologickeho ustavu 71(4): 333-349.

Vavrdová, M.; Isaacson, P.E.; Díaz, E.; Bek, J. 1993. Devonian-Carboniferous boundary at Lake Titikaka, Bolivia: preliminary palynological results. In Congrès International de la Stratigraphie et Géologie du Carbonifère et Permien, No.12, Comptes Rendus 1: 187-200. Buenos Aires.

Vistalli, M.C. 1999. Cuenca Siluro-Devónica. In Congreso Geológico Argentino, No. 14, Relatorio 1: 168-184. Salta.

Young, G.C. 1996. Devonian. In An Australian Phanerozoic Timescale (Young, G.C.; Laurie, J.R.; editors). Oxford University Press 4: 96-109. Melbourne. 
LÁMINAS 1-6 


\section{LÁMINA 1}

Asociación 1 en la Formación Los Monos. Escala gráfica: $20 \mu \mathrm{m}$

Figuras

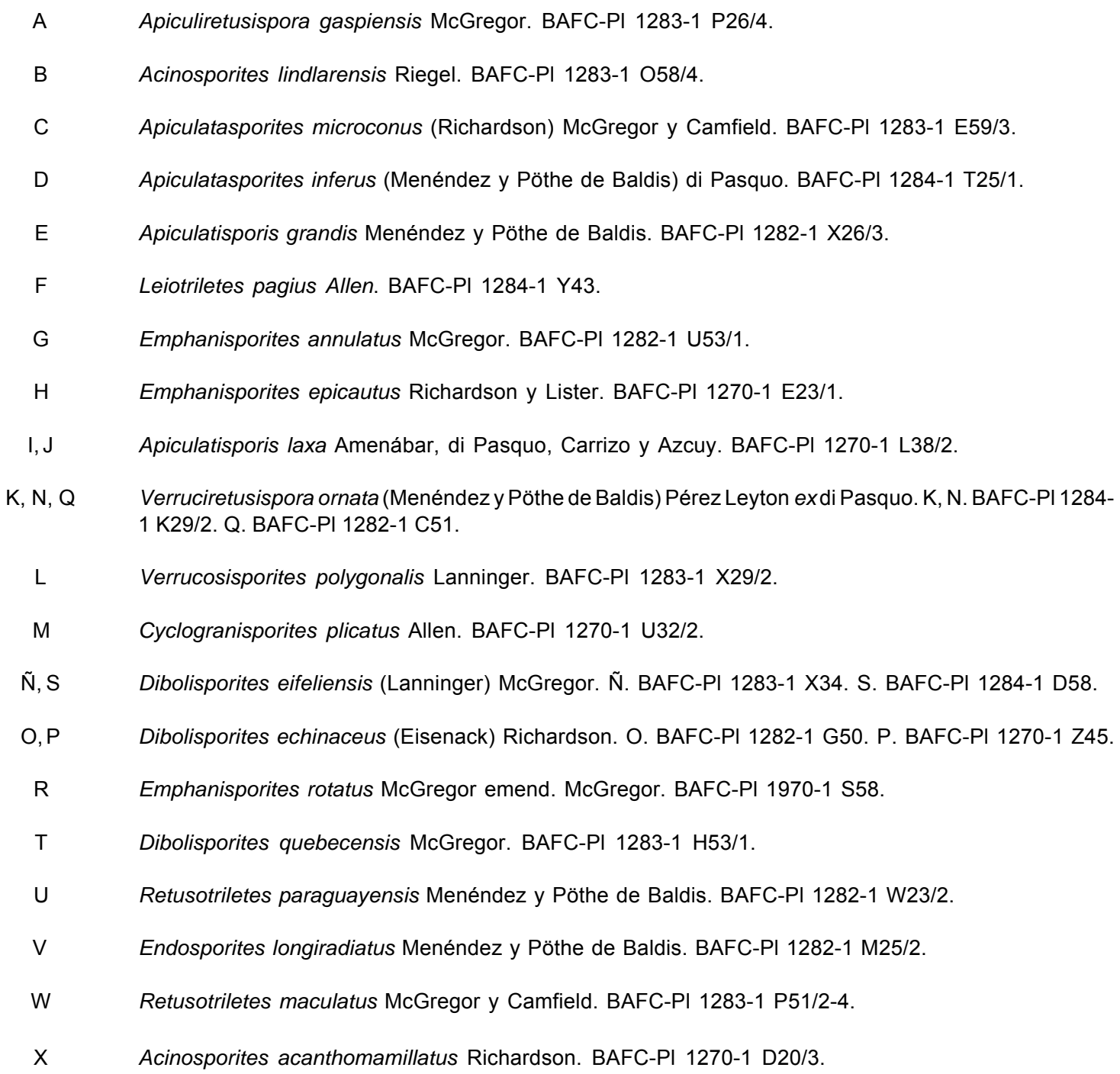



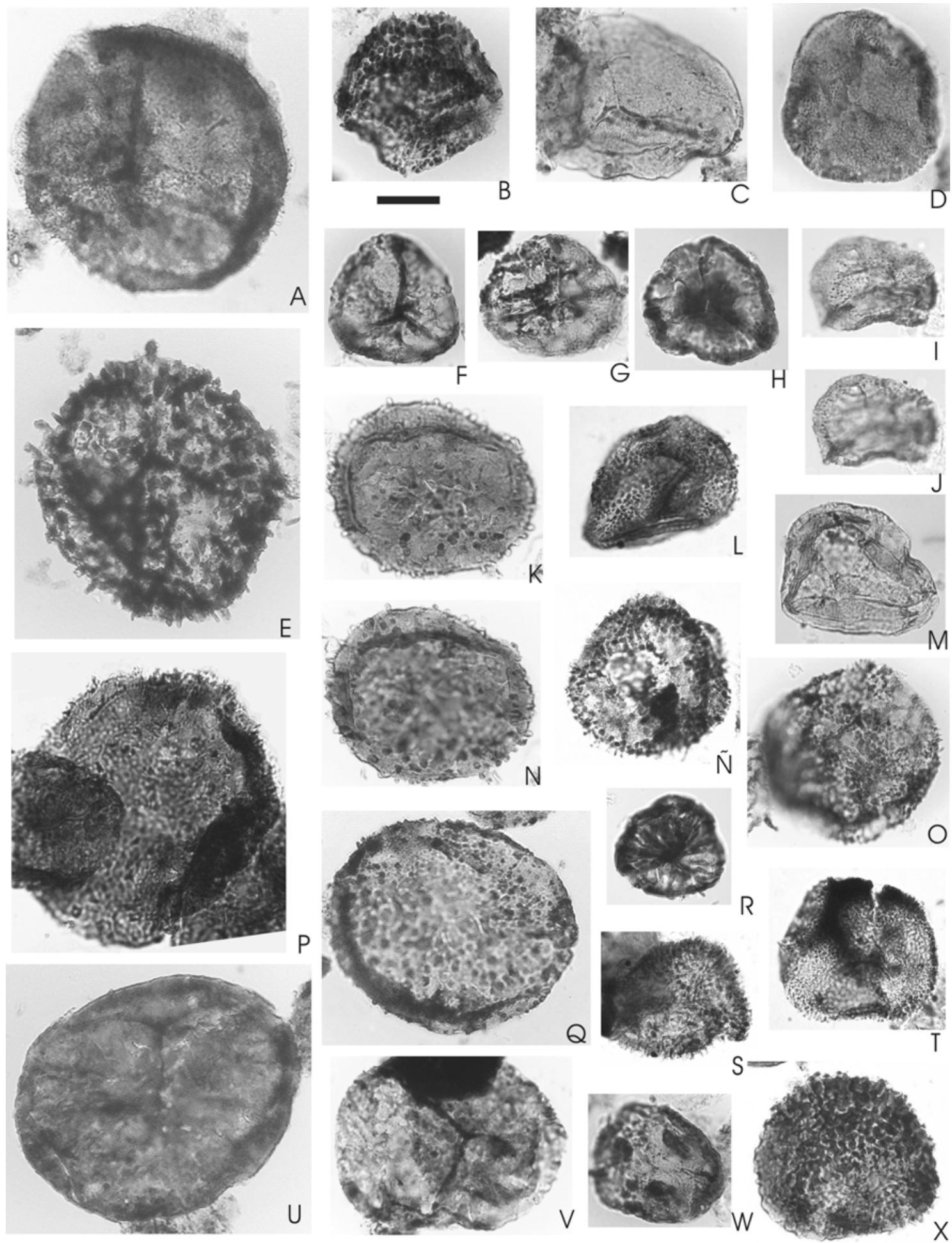


\section{LÁMINA 2}

Asociación 1 en la Formación Los Monos. Escala gráfica: L, N, Ñ, Q $40 \mu \mathrm{m}$; las restantes $20 \mu \mathrm{m}$

Figuras

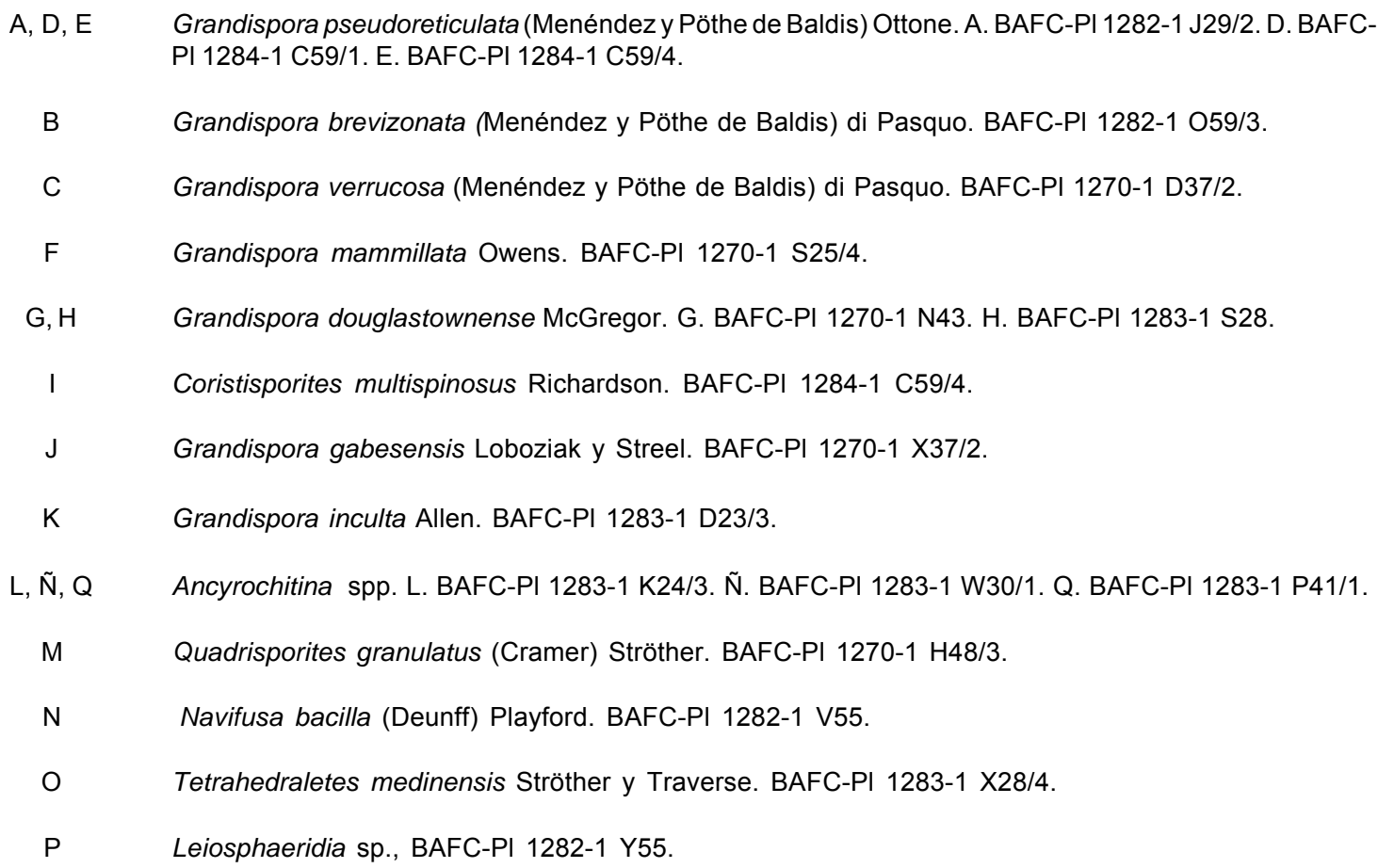



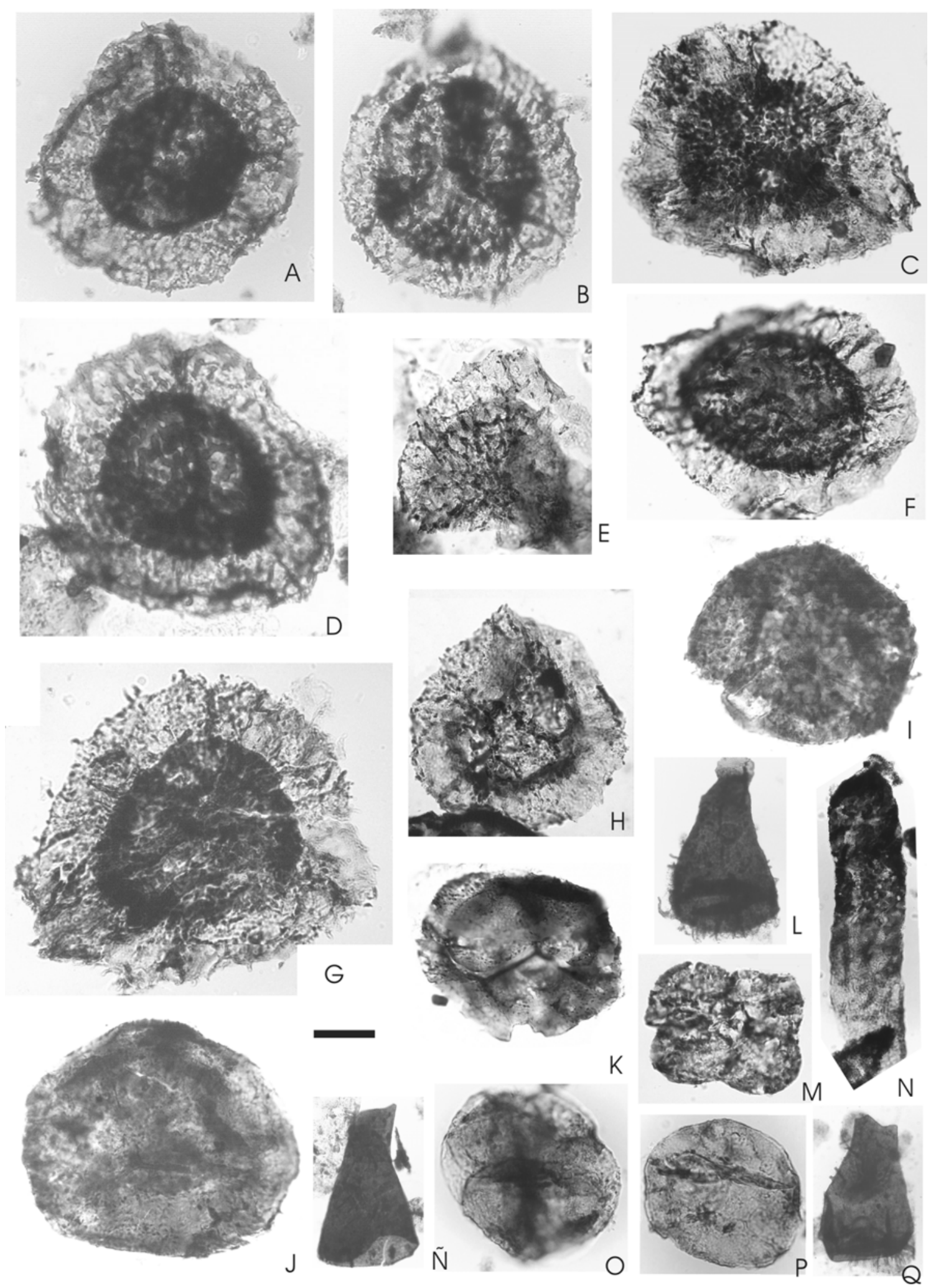


\section{LÁMINA 3}

Asociación 2 en la Formación Los Monos. Escala gráfica: T, AD $10 \mu \mathrm{m}$; las restantes $20 \mu \mathrm{m}$.

Figuras

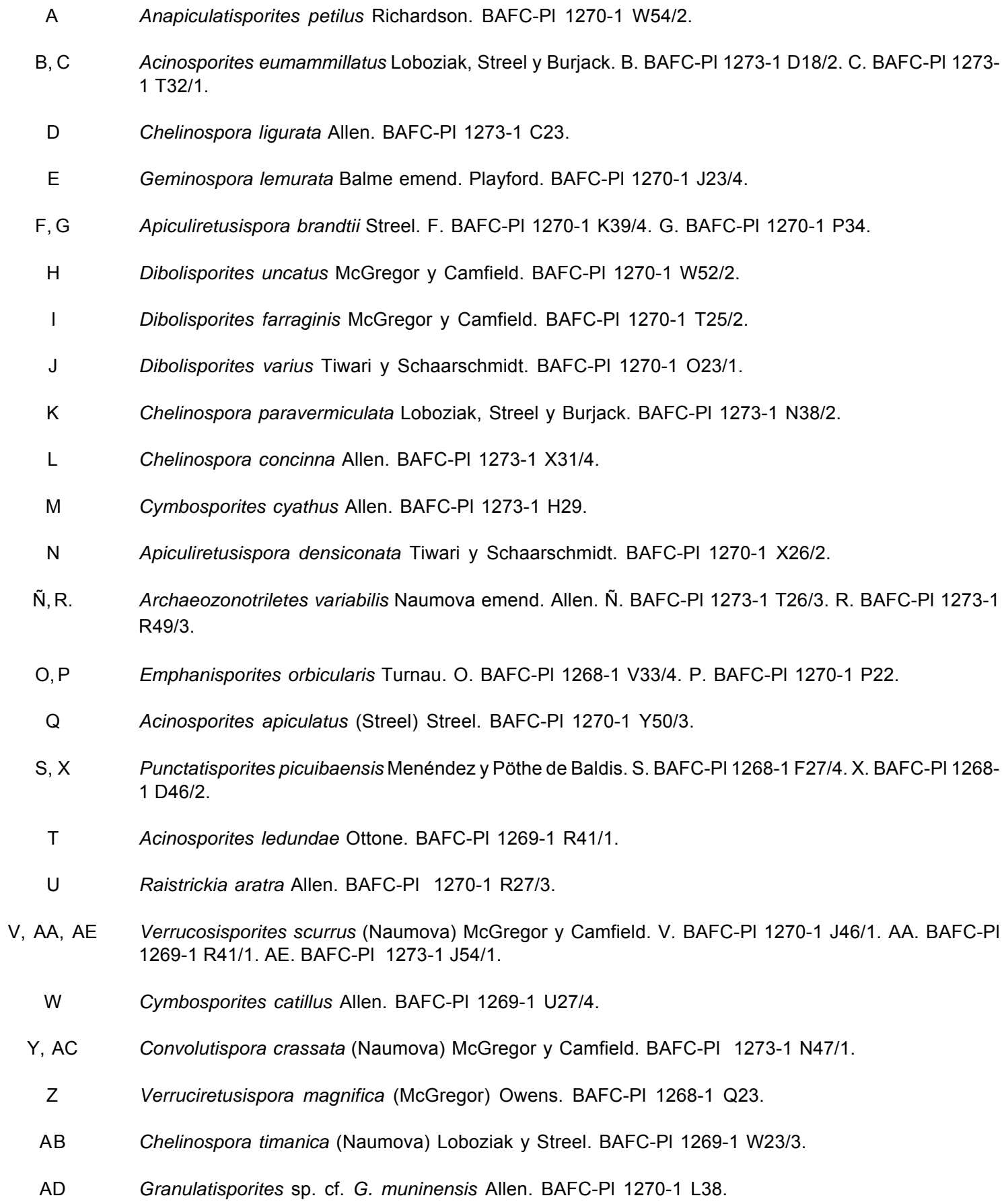



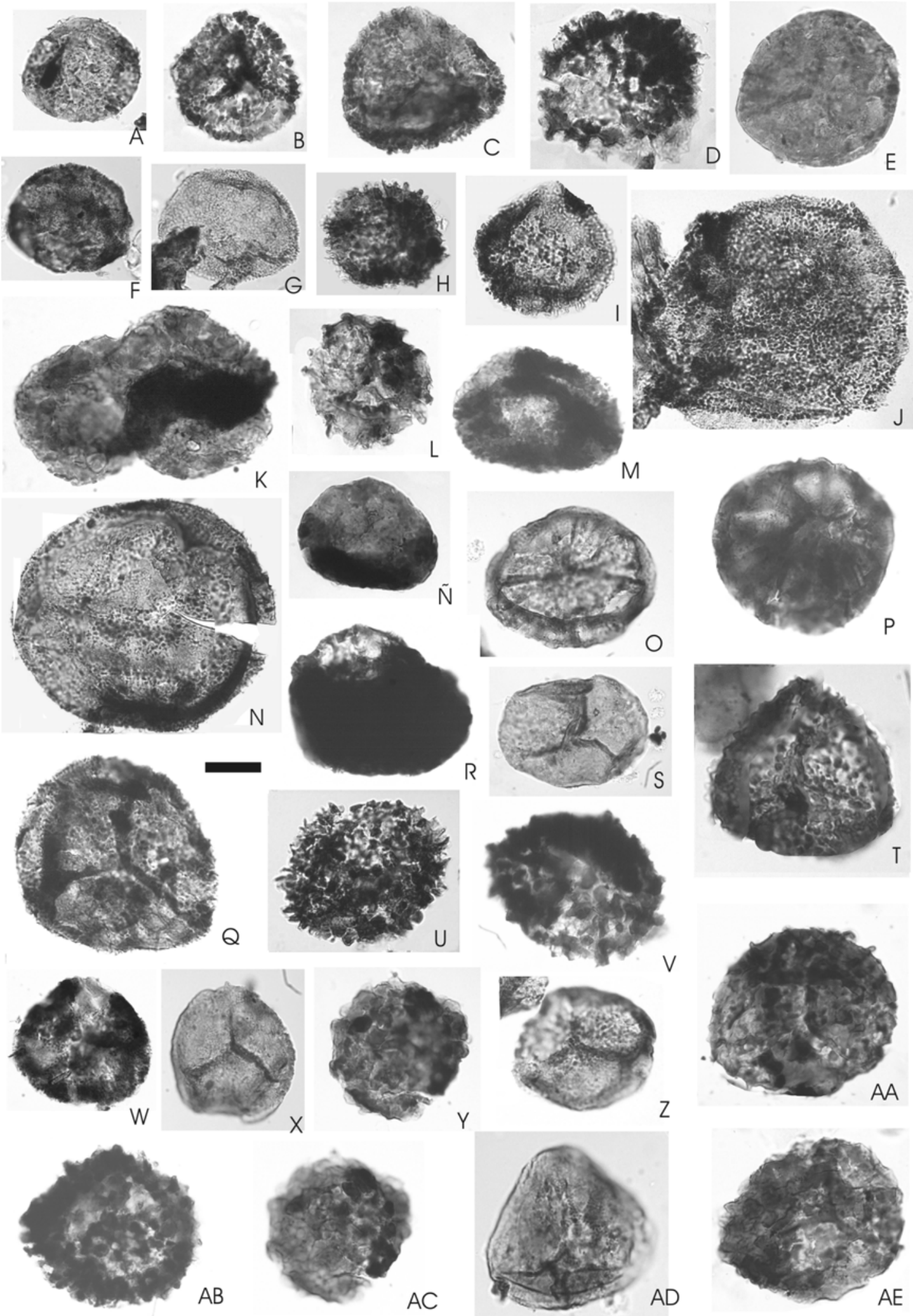


\title{
LÁMINA 4
}

Asociación 2 en la Formación Los Monos. Escala gráfica: $20 \mu \mathrm{m}$.

\author{
Figuras \\ A Grandispora megaformis (Richardson) McGregor. BAFC-PI 1269-1 R52. \\ B Grandispora pseudoreticulata (Menéndez y Pöthe de Baldis) Ottone. BAFC-PI 1269-1 Y35/2. \\ C Grandispora protea (Naumova) Moreau-Benoit. BAFC-PI 1268-1 Z35/4. \\ D Dibolisporites variegatus McGregor. BAFC-PI 1270-1 Z60/1. \\ E, J Grandispora daemonii Loboziak, Streel y Burjack. E. BAFC-PI 1270-1 Z60/1. J. BAFC-PI 1268-1 E48. \\ F Grandispora permulta (Daemon) Loboziak, Streel y Melo. BAFC-PI 1269-1 U49. \\ G, N, T Samarisporites triangulatus Allen. G. BAFC-PI 1269-1 R39/1. Ñ. BAFC-PI 1270-1 M22. T. BAFC-PI 1269- \\ 1 P56/3-4. \\ H Leovolancis divellomedia (Chibrikova) Burgess y Richardson. BACF-PI 1273-1 M50/3-4. \\ I, L Grandispora inculta Allen. BAFC-PI 1269-1 P32/3. \\ K Acinosporites macrospinosus Richardson. BAFC-PI 1270-1 S37/3. \\ M Polyedryxium tectum Deunff 1954. BAFC-PI 1270-1 X25. \\ N Tetrahedraletes medinensis Ströther y Traverse. BAFC-PI 1273-1 Q40/4. \\ O Samarisporites praetervisus Allen. BAFC-PI 1273-1 M20/3. \\ $\mathrm{P}, \mathrm{Q} \quad$ Chomotriletes vendugensis Naumova. P. BAFC-PI 1269-1 X37/3. Q. BAFC-PI 1268-1 Z36/3. \\ R Verhyachium trispininflatum Cramer. BAFC-PI 1273-1 T49. \\ S Hemiruptia legaultii Ottone. BAFC-PI 1270-1 B26/2.
}



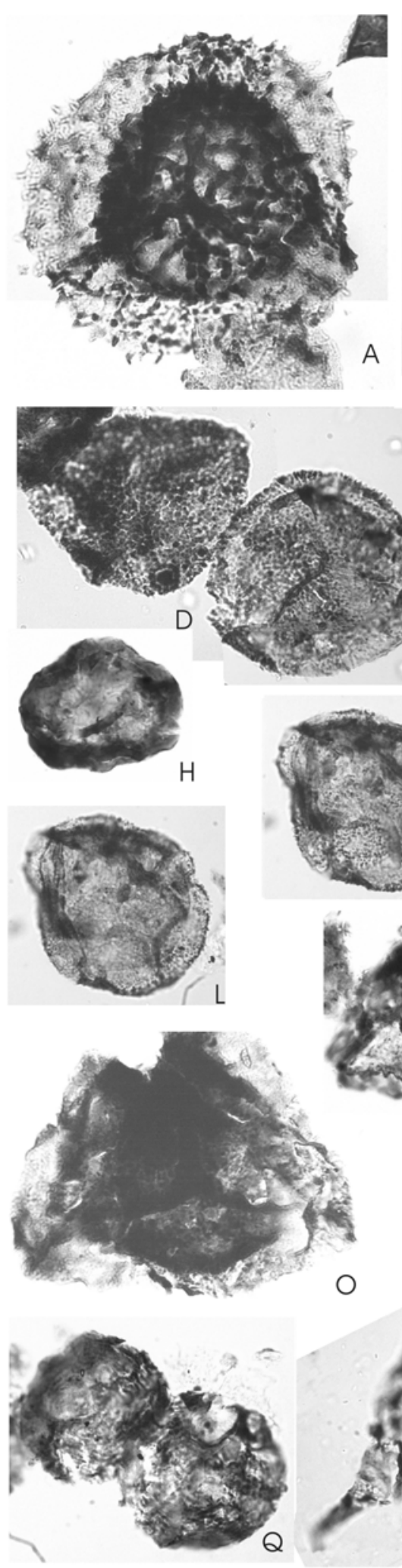
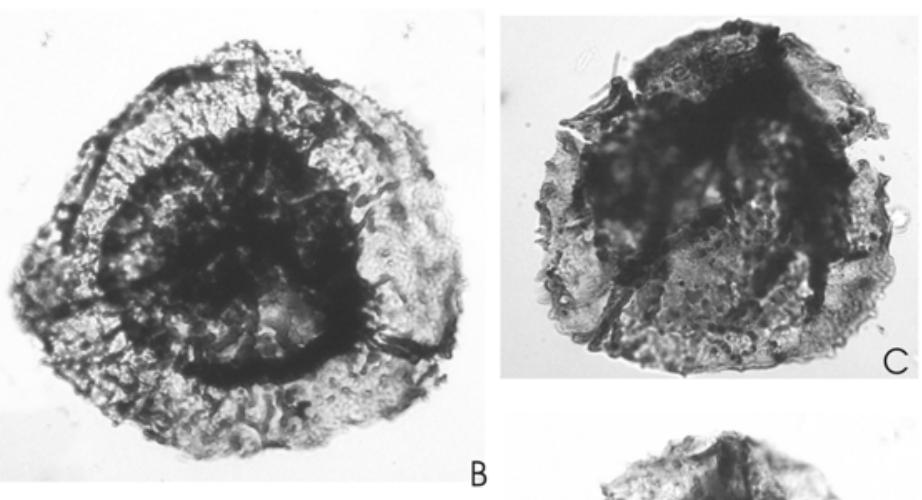

B
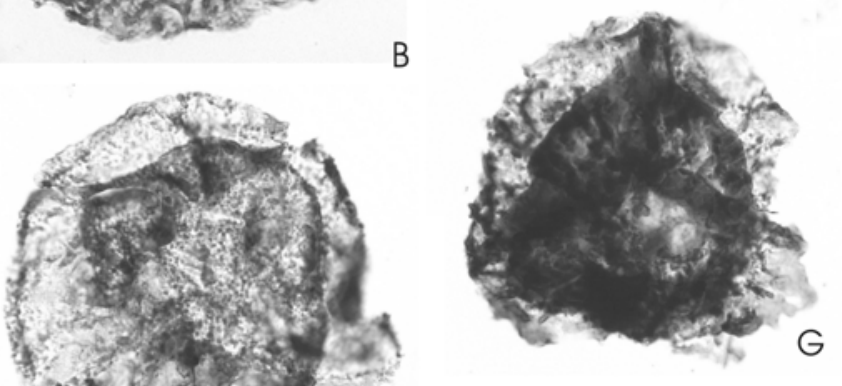

$x^{2} \times y^{2}$
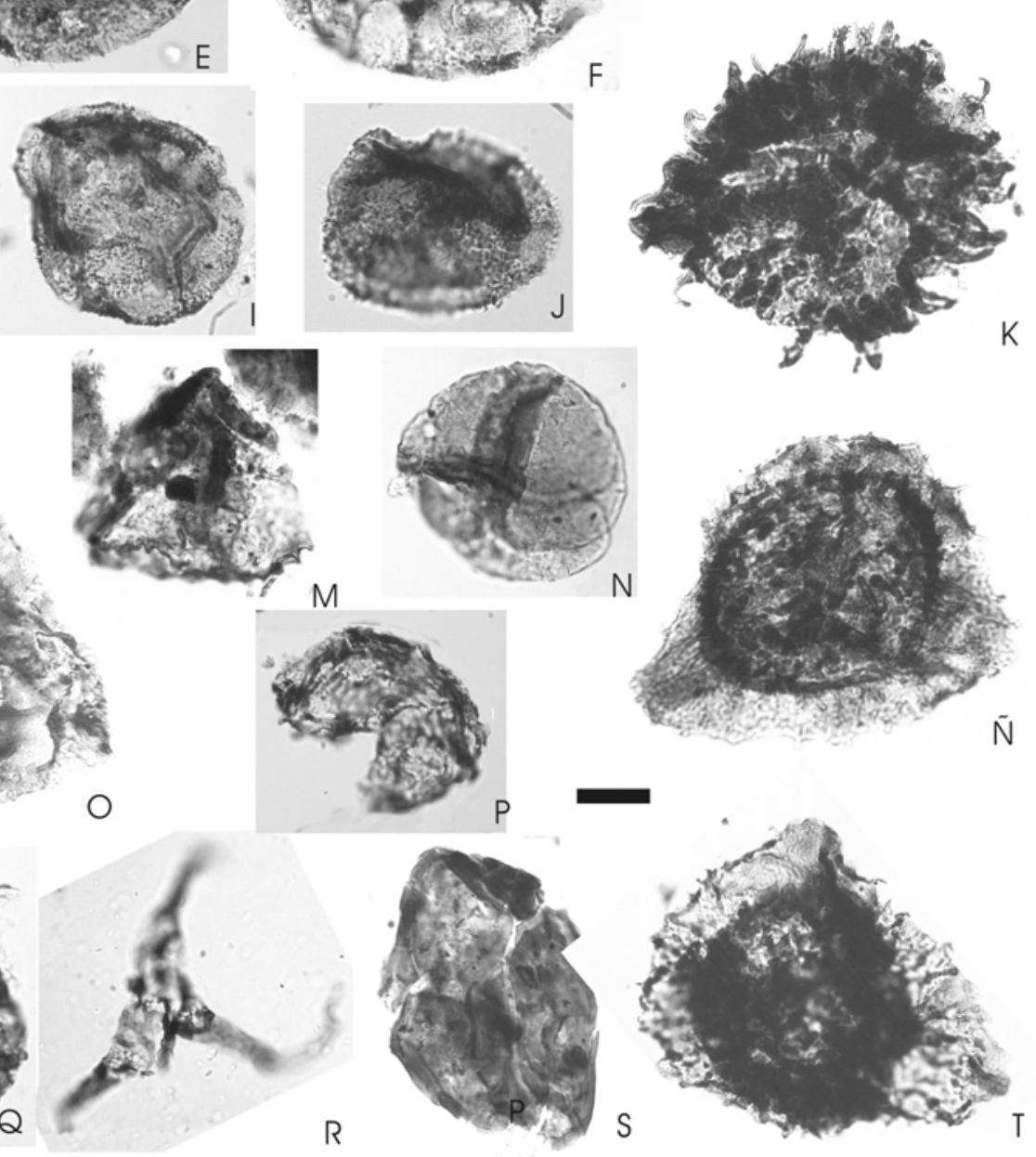


\section{LÁMINA 5}

Asociación 2 en la Formación Los Monos. Escala gráfica: A, B, E $20 \mu \mathrm{m}, \mathrm{L} 13 \mu \mathrm{m}$; las restantes 40 $4 \mathrm{~m}$.

Figuras

A, C, H-O Biharisporites parviornatus Richardson. A. BAFC-PI 1269-1 X26/3. C. BAFC-PI 1273-1 O23/4. H, I, K, L. BAFC-PI 1269. MEB y microscopio óptico del mismo ejemplar. J. BAFC-PI 1269-1 N20/3. M, O. BAFCPI 1269-1. N. BAFC-PI 1269-1 M58. Ñ. BAFC-PI 1273-1 T19/2.

B, F Quitinozoarios indeterminados. B. BAFC-PI 1270-1 R31/1. F. BAFC-PI 1273-1 L21/4.

D Aulicosporites sp. BAFC-PI 1270-1 B25/4.

E Quadrisporites variabilis (Cramer) Ottone y Rossello. BAFC-PI 1268-1 D40.

G Aulicosporites vitabilis Allen. BAFC-PI 1268-1 Z32/1. 


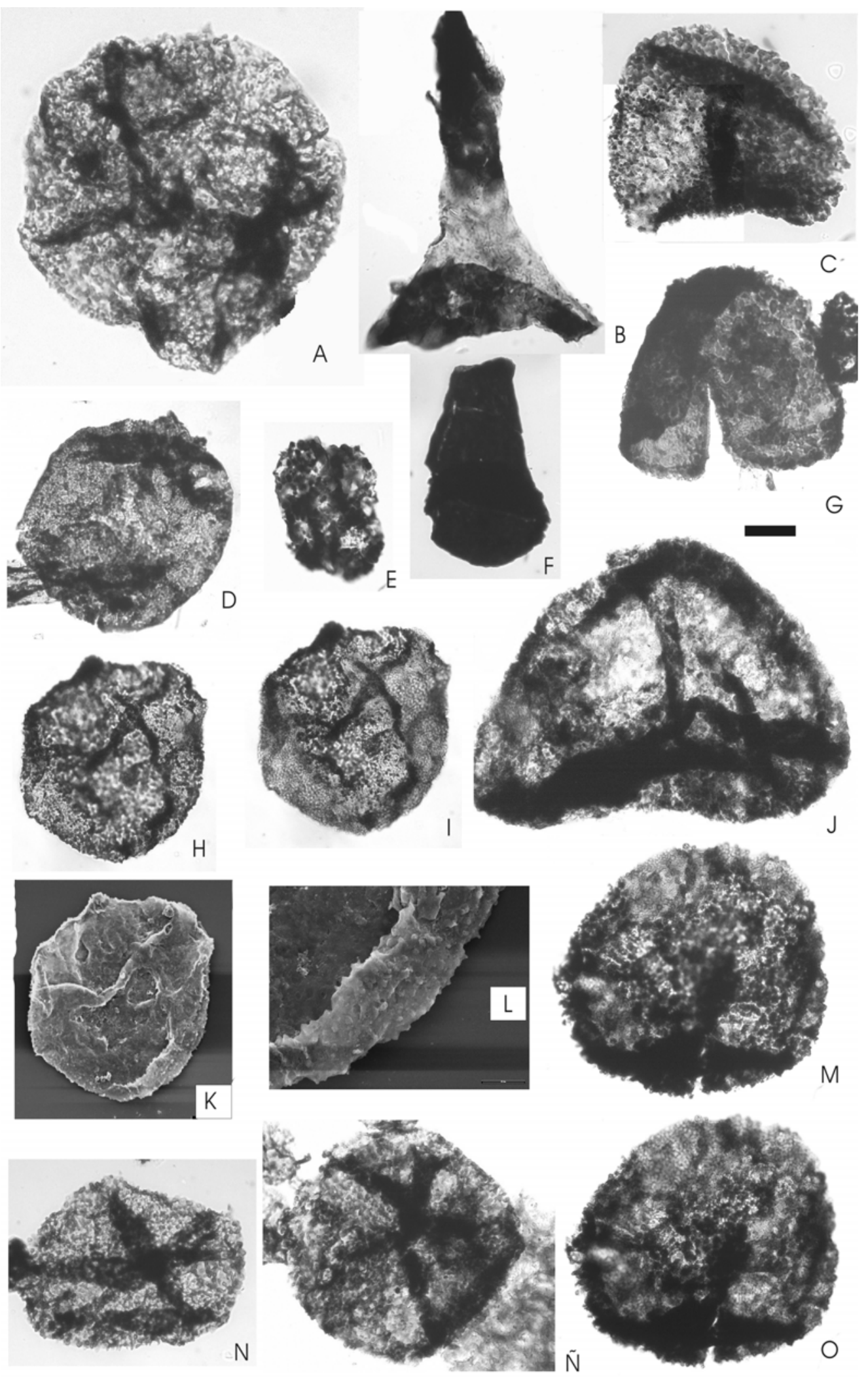




\section{LÁMINA 6}

Especies nuevas y fitoclastos presentes en la asociación 2 (Formación Los Monos). Escala gráfica: A-E $10 \mu \mathrm{m}$; las restantes $20 \mu \mathrm{m}$.

Figuras

A-E Endoculeospora altobellii sp. nov. A, B. BAFC-PI 1270-1 Z51/2. Paratipo. C. BAFC-PI 1270-1 G38/3. Paratipo. D. BAFC-PI 1268-1 Q22/2. Holotipo. E. BAFC-PI 1269-1 O20 Paratipo.

F-I Leiotriletes balapucensis sp. nov. F. BAFC-PI 1270-1 X30/1. Paratipo. G. BAFC-PI 1270-1 Z58. Paratipo. H. BAFC-PI 1268-1 N36. Holotipo. I. BAFC-PI 1273-1 F42/2. Paratipo.

J-L $\quad$ Fitoclastos. J. Traqueida espiralada. BAFC-PI 1270-1 U47. K. Cutícula con estomas abiertos, BAFC-PI 1270-1 W52/2. L. Traqueida espiralada, BAFC-PI 1270-1 E22. 

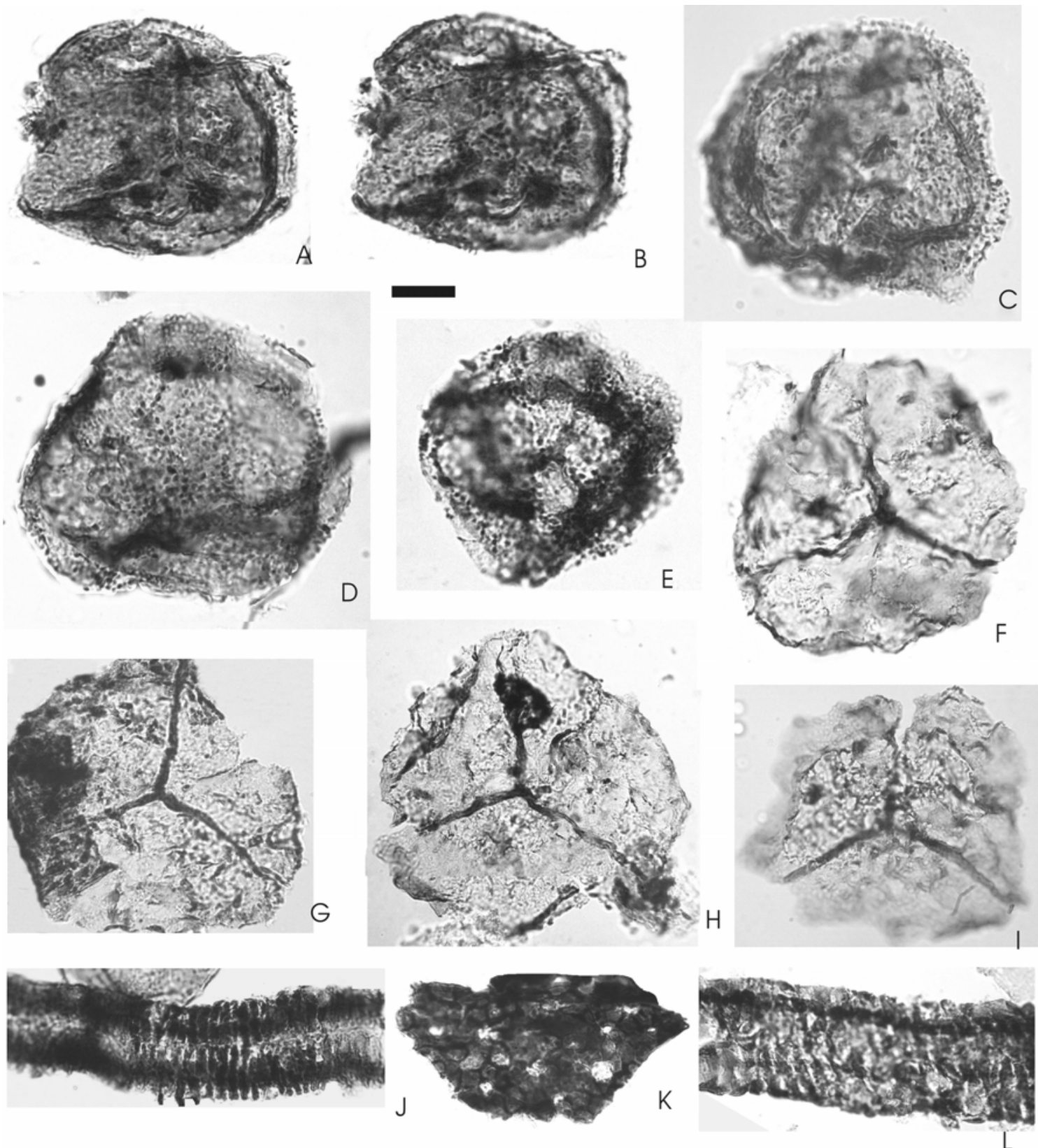


\title{
APÉNDICE. DESCRIPCIONES SISTEMÁTICAS
}

Las especies con asignación abierta no son descritas pues se trata de un solo ejemplar en todos los casos.

\author{
Anteturma Proximegerminantes Potonié, 1970 \\ Turma Triletes Reinsch emend. Dettmann, 1963 \\ Suprasubturma Acavatitriletes Dettmann, 1963 \\ Subturma Azonotriletes Luber emend. Dettmann, 1963 \\ Infraturma Laevigati Bennie and Kidston emend. Potonié, 1956 \\ Género Leiotriletes Naumova emend. Potonié y Kremp, 1954
}

Especie tipo: Leiotriletes sphaerotriangulus (Loose) Potonié y Kremp, 1955. Carbonífero Tardío, Ruhrkarbons (Alemania).

Leiotriletes balapucensis sp. nov. (Lám. 6 F-I) 2006 a Leiotriletes sp. A in Amenábar, di Pasquo, Carrizo y Azcuy; p. 16, Figura 5 E-J.

Holotipo: BAFC-PI 1268-1 N36 (Lámina 6 H). Paratipos: BAFC-PI 1270-1 X30/1; BAFC-PI 1270-1 Z58; BAFC-PI 1273-1 F42/2.

Diagnosis: spore radial trilete, amb subtriangular, with slightly convex sides. Laesurae accompanied by elevated and slightly sinuous labra $3.5-5.8 \mu \mathrm{m}$ high, wider to the pole and extending almost to the equator. Exine smooth to scabrate and thin, 0.6-0.8 $\mu \mathrm{m}$ thick. Frequent exinal foldings.

Derivatio nominis: referido a la localidad homónima. Descripción: espora radial trilete acavada, contorno subtriangular de ápices redondeados y lados rectos a levemente convexos, margen liso cuando está completo. Lesura acompañada por labios algo sinuosos, 3,5-5,8 $\mu \mathrm{m}$ de alto el cual disminuye hacia el ecuador. Exina lisa a escabrada y delgada, $0,6-0,8 \mu \mathrm{m}$ de espesor, con frecuentes pliegues.

Dimensiones: (12 especímenes) diámetro ecuatorial 80-125 $\mu \mathrm{m}$.

Comentarios: los especímenes muestran en general un contorno incompleto, roto debido a su delgada exina si bien la forma de la espora se mantiene gracias a la presencia de la marca trilete labiada. Leiotriletes sp. A in Amenábar, di Pasquo, Carrizo y Azcuy (2006 a) es coespecífica con la especie aquí definida y permite ampliar su registro al Devónico Medio de la Formación Chigua, en la Cuenca Uspallata-Iglesia.

Comparación: Leiotriletes pyramidalis (Luber) Allen 1965 (ilustrada por Tiwari y Schaarschmiidt, 1975, pl. 1, Figs. texto 5-6), es similar pero tiene un contorno bien definido y una exina más gruesa.

Infraturma Retusotrileti Streel ex Becker, Bless, Streel y Thorez, 1974 Género Apiculiretusispora Streel 1964 emend. Streel, 1967

Especie tipo: Apiculiretusispora brandtii Streel, 1964. Devónico Medio, Goe (Bélgica).

Apiculiretusispora brandtii Streel, 1964 (Lám. 3 F, G) 1971 Apiculiretusispora nitida Owens, p. 104 , pl. $3,9-11$

Comparación: según Owens (1971), esta especie se diferencia de Apiculiretusispora nitida Owens 1971 sólo por el tamaño, menor en esta última (33-66 $\mu \mathrm{m})$. Sin embargo, en el caso de los ejemplares reconocidos en esta asociación, el diámetro se encuentra en un tamaño que abarca el de ambas especies mencionadas. Además, debido a que ambas aparecen en estratos del Devónico Medio se considera a Apiculiretusispora nitida coespecífica de la especie creada por Streel (1964). 
Suprasubturma Pseudosaccitriletes Richardson, 1965

Infraturma Monopseudosacciti Smith y Butterworth, 1967

Género Endoculeospora Staplin 1960 emend. Turnau, 1975

Especie tipo: Endoculeospora rarigranulata Staplin 1960. Mississippiano tardío, Alberta (Canadá).

Endoculeospora altobellii sp. nov. (Lám 6 A-E)

Holotipo: BAFC-PI 1268-1 Q22/2 (Lám. 6D). Paratipos: BAFC-PI 1270-1 G38/3; BAFC-PI 1270-1 Z51/2; BAFC-PI 1269-1 O20.

Diagnosis: spore radial trilete, camerate, subcircular to subtriangular amb and margin slightly irregular. Laesurae simple, straight to somewhat indistinct or with sinuous lips about $2 \mathrm{~mm}$ broad at pole, length two-thirds to almost the spore radius. Intexine large conformable with the amb, frequently well defined. Exoexine irregularly extended, smooth on the contact faces and outside ornamented with mostly discrete coni, spines, grana and rods, 0.8 to $1.5 \mu \mathrm{m}$ high and $0.5-1.5 \mu \mathrm{m}$ wide, dense and irregularly distributed on the surface. Exoexine thin frequently folded.

Dimensiones: (10 especímenes) diámetro ecuatorial total $45-60 \mu \mathrm{m}$, diámetro de la intexina $40-55 \mu \mathrm{m}$.

Descripción: espora radial trilete, camerada, de contorno subcircular a subtriangular, margen levemente irregular. Lesura simple, recta, poco distintiva pero a veces algo labiada y sinuosa, alcanza $2 / 3$ hasta casi el radio de la espora. Exoexina en áreas de contacto lisa y fuera de éstas ornamentada por mayormente discretos conos, espinas, gránulos y bastones de 0,8 a $1,5 \mu \mathrm{m}$ de alto y 0,5 a $1,2 \mu \mathrm{m}$ de ancho, irregularmente distribuidos. Exoexina delgada de aspecto hialino, irregularmente extendida mostrando una intexina (cuerpo central) de gran tamaño, subcircular muchas veces descentrada. Frecuentes pliegues sin una dirección preferencial.

Derivatio nominis: dedicado con amor a mi marido.

Comparaciones: Craspedispora paranaensis Loboziak, Streel y Burjack, 1988 del Givetiano de Brasil y Craspedispora ghadamisensis Loboziak y Streel, 1989 del Eifeliano-Givetiano de Libia, se diferencian de la nueva especie por su ornamentación de elementos biformes de mayor tamaño y una zona algo más desarrollada. Craspedispora arctica McGregor y Camfield, 1982 del Eifeliano-Givetiano del Artico Canadiense presenta una separación del cuerpo central o cameración no observada en la nueva especie y ausencia de pliegues exinales. Endoculeospora rarigranulata var. densigranulata Staplin, 1960 presenta un cuerpo central más denso y una ornamentación de gránulos. Endoculeospora gradzinskii Turnau, 1975 muestra una intexina más densa, más pequeña y una ornamentación variada pero con dominio de báculas y clavas. 